NOTICE: this is the author's version of a work that was accepted for publication in Earth Science Reviews. Changes resulting from the publishing process, such as peer review, editing, corrections, structural formatting, and other quality control mechanisms may not be reflected in this document. Changes may have been made to this work since it was submitted for publication. A definitive version was subsequently published in Earth Science Reviews, Vol. 113 (2012). DOI: 10.1016/j.earscirev.2012.03.003 


\title{
The Redox Budget of Subduction Zones
}

\author{
K.A. Evans ${ }^{\mathrm{a}, *}$ \\ ${ }^{a}$ School of Applied Geology, Curtin University, GPO Box 1987, WA6845, Australia tel: \\ 0061892664682 \\ fax: 0061892663153
}

\begin{abstract}
Elements that can occur in more than one valence state, such as Fe, C and S, play an important role in Earth's systems at all levels, and can drive planetary evolution as they cycle through the various geochemical reservoirs. Subduction introduces oxidised $\mathrm{Fe}, \mathrm{C}$ and $\mathrm{S}$ in sediments, altered ocean crust, and partially serpentinised mantle lithosphere to the relatively reduced mantle, with shortand long-term consequences for the redox state of the mantle. This then controls the redox state of mantle material added to the lithosphere and atmosphere, such as arc volcanic gases and the magmas that form arc-related ore deposits.

The extent of mantle oxidation induced by subduction zone cycling can be assessed, albeit with large uncertainties, with redox budget calculations that quantify the inputs and outputs to subduction zones. Literature data are augmented by new measurements of the chemical composition of partially serpentinised mantle lithosphere from New Caledonia and ODP 209. Results indicate that there is a net addition of Fe $\left(55 \pm 13 \times 10^{12}\right.$ moles year $\left.^{-1}\right), \mathrm{C}(4.6 \pm 4.0 \mathrm{x}$ $10^{12}$ moles year $\left.^{-1}\right), \mathrm{S}\left(2.4 \pm 0.9 \times 10^{12}\right.$ moles year $\left.^{-1}\right)$, and redox budget ( $5-$ $89 \times 10^{12}$ moles year $^{-1}$ ) at subduction zones. Monte Carlo calculations of redox budget fluxes indicate that fluxes are $46 \pm 12 \times 10^{12}$ moles year $^{-1}$ entering subduction zones, if input and output parameters are assumed to be normally distributed, and $46-58 \times 10^{12}$ moles year $^{-1}$ if input and output parameters are assumed to be log-normally distributed.
\end{abstract}

\footnotetext{
${ }^{*}$ Corresponding author.

Email address: k.evans@curtin.edu.au (K.A. Evans )
} 
Thus, inputs into subduction zones for $\mathrm{Fe}, \mathrm{C}, \mathrm{S}$ and redox budget are in excess of subduction zone outputs. If MORB and plume-related fluxes are taken into account then $\mathrm{Fe}, \mathrm{C}$ and $\mathrm{S}$ fluxes balance, within error. However, the redox budget does not balance, unless the very lowest estimates for the extent of slab oxidation are taken. Thus it is likely that subduction continuously increases the redox budget of the mantle, that is, there is addition of $\mathrm{Fe}, \mathrm{C}$ and $\mathrm{S}$ that are oxidised relative to the $\mathrm{Fe}, \mathrm{C}$ and $\mathrm{S}$ in the mantle.

The fate of this redox budget can be constrained by consideration of element mobility under mantle conditions. If slab fluids are assumed to be dominantly aqueous and relatively low salinity then fluxes of $\mathrm{Fe}^{3+}, \mathrm{C}^{4+}$, and $\mathrm{S}^{6+}$ are limited to less than $10^{9}, 2.3 \times 10^{12}$ moles year $^{-1}$ and $2 \times 10^{12}$ moles year $^{-1}$ respectively by the low solubility of these elements in slab-derived fluids. Nevertheless, such fluxes can produce the increased $f_{\mathrm{O}_{2}}$ inferred for sub-arc mantle from arc lavas after around 10 Ma subduction.

The rest of the redox budget added by the subduction process is likely to be carried to the deep mantle by the slab, and mix slowly with the whole mantle reservoir, depending on the timescale of reincorporation of subducted lithosphere into the mantle. Simple mixing calculations indicate that these fluxes will only cause a measurable difference to mantle redox on a $1 \mathrm{Ga}$ timescale, which is longer than the 550 Ma during which redox budget fluxes are likely to have been at present day levels. However, measurable effects, with potential consequences for the the Earth's evolution may be expected in the future.

Keywords: redox, subduction, iron, carbon, sulfur, cycling 


\section{INTRODUCTION}

2 Subduction zones connect the Earth's interior to the lithosphere and ex3 osphere (atmosphere/oceans) and thus play a central role in the geochemical 4 cycles of many of the major, minor and trace elements. Much attention has been devoted to geochemical fluxes at subduction zones (e.g. Kerrick, 2001; Kerrick and Connolly, 2001; Lecuyer and Ricard, 1999; Plank and Langmuir, 1998; Hayes and Waldbauer, 2006; Kerrick and Caldeira, 1998; Staudigel et al., 1998; Morner and Etiope, 2002) because quantification of these fluxes is necessary if we are to understand the evolution of the atmosphere and oceans with geological time (e.g. Berner, 2001), plate margin volcanism (e.g. Alt et al., 1993), and the formation of ore deposits at convergent margins (e.g. Sun et al., 2004).

Particular attention has been paid to elements that are redox-sensitive, that is, elements that occur in more than one valence state. Examples include Fe (e.g. Lecuyer and Ricard, 1996), C (e.g. Kerrick, 2001; Morner and Etiope, 2002) and S (e.g. Alt et al., 1993). These elements are present in different concentrations and oxidation states in the different lithologies introduced to subduction zones, and are released, commonly after a change in oxidation state, by the processes associated with subduction. For example, carbon is carried into subduction zones as organic carbon $\left(\mathrm{C}^{0}\right)$ in sediments, as secondary carbonates $\left(\mathrm{C}^{4+}\right)$ in carbonated basaltic ocean crust and serpentinised mantle, and as primary carbonate in carbonaceous oozes. Carbon is released from subduction zones as dissolved carbonate e.g. Mottl et al., (2004), devolatilised $\mathrm{CO}_{2}$ and $\mathrm{CH}_{4}\left(\mathrm{C}^{4-}\right)$ (e.g. Connolly, 2005), and carbonate in silicate melts (e.g. Dasgupta et al., 2006). Release may result in return of the carbon to the atmosphere by reflux up the slab to the trench (e.g. Mottl et al., 2004), or volcanism (e.g. Kerrick, 2001), or by devolatilisation/melting and transfer into the mantle wedge (e.g. Dasgupta et al., 2004). The released carbon may be gaseous species such as methane or carbon dioxide, ionic species in solution, e.g. $\mathrm{HCO}_{3}{ }^{-}$or $\mathrm{CO}_{3}{ }^{2-}$, so or melt species. Alternatively, carbon may be transported into the deep man- 
tle (e.g. Kerrick and Connolly, 2001; Yaxley and Brey, 2004), where it may transform to high density carbonate phases, or occur as graphite or diamond. A similarly complex range of alternatives exist for the other redox elements of interest.

Redox-sensitive elements are of interest because they are of importance to life, the Earth's evolution (e.g. Kump and Holland, 1992), and the formation of ore deposits (e.g. Mungall, 2002) . Bacteria have harvested the energy that could be obtained by catalysis of redox reactions since the dawn of life (e.g. Russell et al., 2005). Carbon dioxide is an essential nutrient for plants, and plays a role in the regulation of the atmosphere. Iron, nitrogen and phosphorous availability determine the productivity of the oceans (e.g. Petsch and Berner, 1998). Microbial sulphate reduction fixes sulphur in sediments and is one of the major fluxes that controls the level of atmospheric oxygen (e.g. Petsch and Berner, 1998). Interactions between redox-sensitive elements are also critical. Oxidation (the loss of electrons) cannot occur without reduction (gain of electrons) somewhere within the system considered, because the vast majority of natural systems are uncharged, that is, they cannot carry a net positive or negative charge. Thus, coupled oxidation and reduction in open systems, where a reactant or product may be lost, can drive massive changes in redox state. Examples include the development of the Earth's core (e.g. Wood et al., 2008) and the formation of the atmosphere (e.g. Kump and Holland, 1992).

The oxidising/reducing capacity of a rock is determined by the product of the quantity of each of the redox-sensitive elements present and the oxidation state of those elements (Evans, 2006), and cannot be described conveniently by commonly used intensive variables such as $f_{\mathrm{O}_{2}}$, because such variables, by definition, are independent of the quantity of the elements present and are thus unsuited to the measurement of fluxes (Giggenbach, 1992; Evans, 2006). For this reason, we use the term redox budget to quantify the oxidising or reducing capacity of the rock, where oxidising capacity increases with redox budget. The formal definition of redox budget is given by Evans, (2006) and is summarised in section 2.1 . 
A number of studies have addressed the coupled fluxes of redox-sensitive elements in exospheric systems on a global scale (e.g. Petsch and Berner, 1998; Berner, 2001;Hayes and Waldbauer, 2006). Such studies have been used to draw conclusions on the rise of atmospheric oxygen, and the variation of oxygen with geological time (e.g. Berner, 2001). However, these works have been forced, for want of robust measurements, to assume that crust/mantle - exosphere exchanges of the redox-sensitive elements are at steady state.

Such a situation seems unlikely. Seafloor alteration of oceanic crust involves significant oxidation of primary basalt-hosted iron (Johnson and Semyan, 1996; Zhou et al., 2001), and serpentinisation results in the formation of magnetite coupled with the release of hydrogen and methane into the ocean (e.g. Charlou et al., 1991). Seafloor sediments can contain oxidised carbon in the form of calcareous oozes (e.g. Plank and Langmuir, 1998). The increase in redox budget caused by the addition of this material to the mantle during subduction must either oxidise the mantle, or be coupled with, on some time-scale, an equivalent but opposite change in mantle redox budget as the result of processes at mid-ocean ridges, arcs or in reflux zones at trenches. Secular variation in the systematics of sedimentation (e.g. Canfield, 2004), MORB production rates and subduction geodynamics are difficult to reconcile with the notion of steady state mantle and exospheric redox budgets.

A limited number of studies have addressed global-scale redox fluxes. Lecuyer and Ricard (1999) document an excess of oxidised iron in subduction zone inputs relative to outputs, and conclude that the Earth's core may be gradually oxidising to compensate. Hayes and Waldbauer (2006) conclude that $\mathrm{CO}_{2}$ from the mantle continually adds to the redox budget of the exosphere, which implies that the mantle redox budget is decreasing i.e. the mantle is becoming more reduced. A number of studies (e.g. Kelley and Cottrell, 2009; Parkinson and Arculus, 1999) propose that sub-arc mantle is more oxidised that that at BAB (Back Arc Basin) or MOR (Mid Ocean Ridge) settings as a result of subduction zone processes. The significance of such such oxidation was assessed by Hirschmann (2009) who calculated that $40 \%$ of the Earth's mantle has cycled 
through these oxidised mantle wedge environments over geological time. In spite of these conclusions, there is little conclusive evidence that the oxidation state of the mantle as a whole has changed significantly over geologic time (e.g. Delano, 2001; Lee and Li, 2004).

The motivation to understand the evolution of the redox budgets of the different reservoirs is strong. The control on redox state that is exerted by fluxes of redox-sensitive elements is responsible for the secular evolution of the mantle and atmosphere, the potential oxidation of arc-magma source zones, with implications for the development of ore deposits (Mungall, 2002), the release of sulphur aerosols from arc volcanism (e.g. de Hoog et al., 2004), and, potentially, for climate extremes such as the Paleocene-Eocene thermal maximum (e.g. Svensen et al., 2004).

However, there are a number of factors that prevent reliable quantification of subduction-related fluxes of redox-sensitive elements. Subduction input fluxes are heterogeneous along the 44,450 km (Jarrard, 2003) of active subduction zone, and the inaccessible nature of these regions complicates acquisition of reliable data. Nevertheless, the composition of sediments and cooling-related hydrothermal alteration of the ocean crust have been constrained from measurements on a large number of ocean cores (e.g. Plank and Langmuir, 1998; Jarrard, 2003). The redox budget contribution from partially serpentinised mantle lithosphere, on the other hand, is poorly constrained but potentially significant (e.g. Skelton et al., 2005; Ranero and Sallares, 2004) because serpentinisation reactions create magnetite (e.g. Frost and Beard, 2006).

Outputs from subduction zones are even more difficult to quantify. Volcanism is spatially and temporally heterogeneous, and access to degassing magma chambers is limited, so quantification of volcanic outputs is necessarily subject to large uncertainties. Non-volcanic fluid outputs are thought to be very large (e.g. Mottl et al., 2004; Bebout, 1995) but are diffuse and commonly sub-aqueous, so that measurement is challenging. Additionally, processes such as mineral precipitation, the entrainment of seawater, and microbial processes such as sulphate reduction, alter the chemistry of fluids in the sub-surface envi- 
ronment. Subduction zone outputs into non-exospheric reservoirs, such as the mantle wedge and the deep mantle, can only be estimated by difference or from exhumed material, and in the latter case, the possibility of modification of the subduction signature by the exhumation process has to be accounted for.

Here, redox budget fluxes into, and out of, subduction zones are estimated. Data used to estimate fluxes are mostly taken from the literature, but new data are presented that constrain the fluxes related to partially serpentinised mantle lithosphere. The extent to which these fluxes are offset by MORB and plumerelated magmatism is discussed, and the consequences of subduction zone redox budget fluxes for the spatial and temporal evolution of mantle redox state are evaluated.

\section{Material and Methods}

\subsection{Conceptual Model}

For the purposes of this study, the subduction zone is assumed to comprise (Figure 1) a downgoing slab of altered ocean crust (AOC), that is overlain by sediment, and supported by partially serpentinised mantle lithosphere. The overriding lithosphere, of unspecified composition, supports a volcanic arc, which occurs above a wedge of sub-arc mantle. There may be partially serpentinised mantle wedge overlying the subducting slab (e.g. Hattori and Guillot, 2007 ) but this is not considered separately in the model. Inputs into the subduction zone are the sediments, the AOC, and partially serpentinised mantle lithosphere. AOC is assumed to consist of ocean crust $6 \mathrm{~km}$ thick, which includes $4 \mathrm{~km}$ of gabbro and $2 \mathrm{~km}$ of basalt, after Lecuyer and Ricard (1999). Outputs are volcanic rocks and gases from the arc, and non-volcanic fluid release up the surface of the subducting slab. Any difference between the inputs and outputs is assumed to be added to either the sub-arc mantle, or the deep mantle after slab incorporation into the mantle, but the proportion added to each reservoir can only be assessed qualitatively.

Figure 1 near here 
Tectonic accretion and erosion at the subduction interface are not considered explicitly, as it is assumed that they balance on some geological timescale. The model does not consider the effects of subduction of ore deposits, the formation of ore deposits, or the subduction of continental crust. The main reason for these omissions is that quantification of compositions and fluxes on a global scale is difficult for these sources, due to their chemically, spatially and temporally heterogenous nature. However, ore deposits, although containing locally high concentrations of certain elements, particularly sulfur, are unlikely to provide a significant contributor to global elemental or redox budgets because of their relative rarity. Continental crust is much more common but it's buoyancy means that subduction is mostly ineffective. Return to the Earth's surface of partially subducted contentinental crust is well documented (e.g. Zhang et al., 2008) in high pressure and ultra-high pressure metamorphic terrains. The volume of such partially-subducted continental material is known to be small, but the volume of fully-subducted material is unknown.

Each component flux is made up of contributions from all the redox-sensitive elements, Fe, C, S, O, H, N, P, U, and so on. Here, we focus on Fe, C, S, O and $\mathrm{H}$ in detail; the other elements are neglected because they do not contribute significantly to redox budget on the global scale, even though they may be significant locally, and can provide a useful record of intensive redox variables such as $f \mathrm{O}_{2}$. The object of the exercise is to review evidence from the literature for the magnitude of the subduction-related fluxes, and to make a best estimate, with uncertainties, for the fluxes of each component.

The overall effect of the fluxes on the oxidising capacity of the reservoirs is assessed by calculation of the redox budget (Evans, 2006). The redox budget of a rock is defined as the number of moles of electrons that need to be added to the rock to reach a given reference state:

$$
R B=\sum_{i} n_{i} \nu_{i},
$$

where $R B$ is the redox budget, $n_{i}$ is the number of moles of redox state $i$ 
present in the sample of interest, and $\nu_{i}$ is the number of electrons required to take one mole of redox state $i$ to the reference redox state. For example, the redox budget of two moles of $\mathrm{FeO}$ with respect to a reference state of $\mathrm{Fe}$ as $\mathrm{Fe}^{3+}$ and $\mathrm{O}$ as $\mathrm{O}^{2-}$ is -2 , because 2 moles of electrons would need to be removed to oxidize the $\mathrm{Fe}^{2+}$ to $\mathrm{Fe}^{3+}$. It should be noted that some reference states for redox budget are hypothetical, because a reservoir in which all elements were present at the reference valence state might be charged. However, this does not affect the validity or usefulness of the concept. For the purposes of this study, two different reference states are considered. The first is mantle-like; that is, Fe is considered to be present as $\mathrm{Fe}^{2+}, \mathrm{C}$ as $\mathrm{C}^{0}, \mathrm{O}$ as $\mathrm{O}^{2-}, \mathrm{H}_{\text {as }} \mathrm{H}^{1+}$ and $\mathrm{S}_{\text {as }} \mathrm{S}^{2-}$. Redox budgets relative to this reference state are shown with the subscript $M$. The second is crust-like; that is, Fe is considered to be present as $\mathrm{Fe}^{3+}, \mathrm{C}$ as $\mathrm{C}^{4+}, \mathrm{O}$ as $\mathrm{O}^{2-}, \mathrm{H}_{\text {as }} \mathrm{H}^{1+}$ and $\mathrm{S}$ as $\mathrm{S}^{6+}$. Redox budgets relative to this reference state are shown with the subscript $C$.

Redox budget is an extensive variable, that is, it is independent of the quantity of material considered. However, it is also useful to be able to define redox budget for a unit mass or quantity, for which the term specific redox budget $(\overline{R B})$ can be used. For example, in section 4, we use a specific redox budget $(\overline{R B})$ with the units of moles $\mathrm{kg}^{-1}$. It is also useful to define a symbol for redox budget fluxes, that is, the rate of change of redox budget with respect to time, and for this the notation $\dot{R B}$ is used.

Redox budget is the most appropriate variable for use in studies of this type because it allows: quantification of fluxes, unlike intensive redox variables such as $f_{\mathrm{O}_{2}}$, which are independent of the quantity of material considered; consideration of the combined effect of fluxes of redox sensitive elements, without the need to consider interchanges in valence between those elements explicitly; and, by specification of different appropriate reference states, consideration of the effect of subduction on mantle and exospheric geochemical reservoirs. 


\subsection{Input Fluxes}

\subsubsection{Sediments}

Most of the information on sediment inputs into subduction zones are taken from the Plank and Langmuir (1998) comprehensive study of the material delivered to the world's subduction zones, updated to reflect new estimates of convergence rates recorded by Jarrard (2003). Other estimates integrated into the assessment are those of Rea and Ruff (1996), Lecuyer and Ricard (1999), and Von Huene and Scholl (1991).

Estimates of the total mass of sediments subducted each year range from 1.0 (Hay et al., 1988) to $4.0 \times 10^{12} \mathrm{~kg} \operatorname{year}^{-1}$ (Von Huene and Scholl, 1991). The preferred estimate here is that of Plank and Langmuir (1998), updated in line with the suggestions of Jarrard (2003), to reflect updated convergence rates and subduction zones not sampled by Plank and Langmuir (1998). The assumed value for the total subducted sediment flux is $1.73 \times 10^{12} \mathrm{~kg}_{\mathrm{year}}^{-1}$, which includes 8 weight $\%$ water. A somewhat arbitrary uncertainty of $20 \%$ of the total is assigned to this value.

Carbon Holser et al (1988) estimated the rate of subduction of organic carbon to be $0.2 \times 10^{12}$ moles year ${ }^{-1}$. Wallman (2001) estimates that the sedimenthosted flux of organic carbon into subduction zones is $0.54 \times 10^{12}$ moles year $^{-1}$, based on the input flux of terrigenous and biogenic sediments, at $1 \times 10^{12} \mathrm{~kg}$ year $^{-1}$ and $2 \times 10^{11} \mathrm{~kg}_{\text {year }}{ }^{-1}$ respectively (Plank and Langmuir, 1998), and the organic content of these sediments, which are 0.6 wt $\%$ and 0.25 wt $\%$. Bebout (1995) based on a 1 wt\% average organic carbon content, estimates an annual flux of 1.1 to $2.9 \times 10^{12}$ moles year $^{-1}$, but this is based on a possibly unrealistically high proportion of subducted pelitic material.

Rea and Ruff (1996) estimated that $1.8 \times 10^{13}$ moles of carbonate-hosted carbon are subducted each year. Plank and Langmuir (1998) estimated that $0.9 \times 10^{12}$ moles of carbonate carbon are subducted each year. A significantly higher estimate is provided by the compilation of Jarrard (2003), who estimates that total global subduction of sediment-hosted $\mathrm{CO}_{2}$ is $4.25 \times 10^{12}$ moles year ${ }^{-1}$. 
Here, we assume that the average subducted sediment is $3 \pm 1.4$ weight $\%$ carbon as $\mathrm{CO}_{2}$ in carbonate, after Plank and Langmuir (1998), which gives a carbonate carbon flux of $1.18 \pm 0.60 \times 10^{12}$ moles year ${ }^{-1}$. The uncertainty on the flux is calculated by standard error propagation from the uncertainties of the initial carbonate content and the sediment flux value, assuming that the two parameters are uncorrelated. For zero valent carbon, we take the Wallman estimate of $0.54 \times 10^{12}$ moles year ${ }^{-1}$, and increase it by one third, to account for the subduction zones not investigated by Plank and Langmuir (Jarrard, 2003), to give $0.72 \pm 0.39 \times 10^{12}$ moles year ${ }^{-1}$, equivalent to an average organic carbon content of $0.5 \pm 0.25 \mathrm{wt} \%$ in subducted sediments. The $50 \%$ uncertainty on the latter figure is arbitrary and reflects the wide range of literature estimates.

Iron Chester (1990) estimates that ocean sediments have an average total iron content of $4.17 \mathrm{wt} \%$, and that the $\mathrm{Fe}^{3+} / \mathrm{Fe}_{\text {tot }}$ of this material is 0.82 . The concentration is consistent with the analysis of Plank and Langmuir (1998), who give a value of $5.41 \pm 0.42$ wt $\% \mathrm{FeO}$. Here we assume a $\mathrm{Fe}^{2+}$ content of $0.72 \mathrm{wt} \%$ and an $\mathrm{Fe}^{3+}$ content of $3.28 \mathrm{wt} \%$, with uncertainties of $8 \%$ relative on each. The total iron is equal to $5.14 \mathrm{wt} \%$ as $\mathrm{FeO}$ or $5.72 \mathrm{wt} \%$ as $\mathrm{Fe}_{2} \mathrm{O}_{3}$. The sediment-hosted flux of $\mathrm{Fe}^{2+}$ and $\mathrm{Fe}^{3+}$ into subduction zones is therefore 0.22 \pm 0.05 and $1.02 \pm 0.22 \times 10^{12}$ moles year $^{-1}$ respectively.

Sulphur Pyrite is relatively rare in deep sea sediments (Canfield, 2004), and estimates of the sulphur content of subducting sediments were not presented in the Plank and Langmuir (1998) compilation. Here we follow the approach of Canfield (2004) and assume that approximately 1 wt \% Fe in deep sea sediments is available for pyrite formation (Raiswell and Canfield, 1998), which gives a S content for these sediments of $1.15 \mathrm{wt} \%$. This value is a maximum for the case where all subducting sediments have undergone pyrite formation in the sulphide stability field, and is given a $50 \%$ relative uncertainty. The calculated sediment flux of $\mathrm{S}^{-}$into subduction zones is therefore $0.62 \pm 0.33 \times 10^{12}$ moles year $^{-1}$. 


\subsubsection{Ocean Crust}

Previous estimates of the mass of ocean crust subducted have been presented by Ito et al. (1983) who estimated a subduction flux of $58.9 \times 10^{15}$ grams year $^{-1}$, and by Peacock (1990) who give a value of $60 \times 10^{15}$ grams year $^{-1}$. Jarrard (2003) estimates that $2.45 \mathrm{~km}^{2}$ of ocean crust is subducted each year. This value is about $1 / 3$ less than that from previous works, mainly because of reductions in estimated plate spreading rates. If this estimate is combined with the assumptions regarding the thickness and composition of AOC given in the conceptual model and an assumed average density of $3100 \mathrm{~kg} \mathrm{~m}^{-3}$, then a subduction flux of $45.6 \times 10^{15}$ grams year ${ }^{-1}$ is calculated. A comparable estimate is provided by Lecuyer and Ricard (1999), who state that the average ocean crust is produced at $65,000 \mathrm{~km}$ of ridge, spreading at $5 \mathrm{~cm}_{\text {year }}{ }^{-1}$, to give a volume of $15.6 \mathrm{~km}^{3}$ year ${ }^{-1}$, implying a subduction flux of $48.4 \times 10^{15}$ grams year $^{-1}$. Crisp (1984) estimates that ocean crust creation proceeds at $21 \mathrm{~km}^{3}$ year $^{-1}$, which implies a subduction flux of $65.1 \times 10^{15}$ grams year $^{-1}$ if rates of crust creation and destruction are taken to be equal. Here, we take the most up to date estimate of Jarrard (2003), with the proviso that this represents a minimum flux. The uncertainty is taken to be $20 \%$ of the total, to reflect the spread of estimates

Carbon The erupted $\mathrm{CO}_{2}$ content of MORB is about 200ppm (Hayes and Waldbauer, 2006). Carbonate is also added, post-eruption, to ocean floor basalts by hydrothermal circulation at the mid-ocean ridge (Staudigel et al. 1989; Alt and Teagle 1999, 2003). Staudigel et al. (1989) undertook a detailed study of material from holes $417 \mathrm{~A}, 417 \mathrm{D}$, and $418 \mathrm{~A}$. A weighted average $\mathrm{CO}_{2}$ concentration for these holes gives $2.95 \mathrm{wt} \%$, indicating substantial $\mathrm{CO}_{2}$ addition. Alt and Teagle (1999) calculated a weighted average for the $\mathrm{CO}_{2}$ content of AOC of $0.21 \mathrm{wt} \%$, and estimated that addition of carbon to ocean crust in the form of carbonate occurs at a rate of 1.5 - 3.4 x $10^{12}$ moles year ${ }^{-1}$. Kerrick (2001) estimated that carbonate formation in MOR hydrothermal systems produces $3.5 \times 10^{12}$ moles year ${ }^{-1}$ of carbonate. A lower estimate is provided by Paul et 
al. (2006), who used measurements from ODP Site 1224, which is less altered than most ocean crust segments. Paul et al. (2006) calculated that, if site 1224 were representative then carbonation of ocean crust would add $0.21 \times 10^{12}$ moles year $^{-1}$ of carbonate to the AOC. This estimate is an order of magnitude smaller than estimates (e.g. Alt and Teagle, 1999) derived from more altered crustal sections. The compilation of Jarrard (2003) indicates that $\mathrm{CO}_{2}$ enrichment is progressive over at least $10 \mathrm{Ma}$, and that the $\mathrm{CO}_{2}$ subduction fluxes depend on the age of subducted crust.

Jarrard incorporates the effect of increasing $\mathrm{CO}_{2}$ with crustal age into calculations to produce an estimate of the subduction flux of $\mathrm{CO}_{2}$ as carbonate in AOC of $2.3 \times 10^{12}$ moles year ${ }^{-1}$. Here, we multiply the average $\mathrm{CO}_{2}$ content of ocean crust obtained by Alt and Teagle (1999) by the Jarrod (2003) estimate of AOC mass flux to obtain an estimate of $\mathrm{C}^{4+}$ subduction rate of $2.2 \pm 0.6 \mathrm{x}$ $10^{12}$ moles year ${ }^{-1}$. The uncertainty is based on an assumed $20 \%$ uncertainty on both the $\mathrm{CO}_{2}$ content and the AOC mass flux.

Iron Lecuyer and Ricard (1999) estimate that ocean basalt has an average $\mathrm{Fe}^{3+} / \mathrm{Fe}_{\text {tot }}$ of $0.26 \pm 0.08$ and a total Fe content (wt \%) of $7.35 \pm 1.45(n=221$, where $n$ is the number of samples in their study), and that gabbro has a an average $\mathrm{Fe}^{3+} / \mathrm{Fe}_{\text {tot }}$ of $0.2 \pm 0.08$ and a total $\mathrm{Fe}$ content (wt \%) of $5.8 \pm 3.6$ $(n=130)$. This gives an average value for the hydrothermally altered ocean crust for $\mathrm{Fe}^{3+} / \mathrm{Fe}_{\text {tot }}$ of $0.22 \pm 0.08$. This value is slightly lower than a previous estimate of 0.24, made by Ronov and Yaroshevsky (1976), but these workers did not take the lesser extent of oxidation in the gabbro section of the ocean crust into account. The value is also comparable to that measured by Lecuyer and Ricard (1999) for ophiolites and back-arc basin basalts, of 0.25. Johnson and Semyan (1994) examined the top 50 metres of basaltic ocean crust using data from all available Deep Sea Drilling and Ocean Drilling Program holes available at that time. They measured an average $\mathrm{Fe}^{3+} / \mathrm{Fe}_{\text {tot }}$ of 0.14 in basalt younger than $5 \mathrm{Ma}$, with an increase to 0.29 at $5 \mathrm{Ma}$, and a further increase to 0.36 between 5 and 20 Ma. Further age increases did not result in further statistically significant changes in $\mathrm{Fe}^{3+} / \mathrm{Fe}_{\text {tot }}$. 
A weighted average of the values given by Lecuyer and Ricard (1999), using the ocean crust structure summarised in the conceptual model, gives an $\mathrm{Fe}^{2+}$ content of AOC of $4.9 \pm 0.59 \mathrm{wt} \%$, and an $\mathrm{Fe}^{3+}$ content of $1.4 \pm 0.62 \mathrm{wt} \%$. The flux of $\mathrm{Fe}^{2+}$ is therefore $40 \pm 9.3 \times 10^{12}$ moles year ${ }^{-1}$, while the flux of $\mathrm{Fe}^{3+}$ is $11.4 \pm 5.6 \times 10^{12}$ moles year ${ }^{-1}$. Uncertainties on iron contents and $\mathrm{Fe}^{3+} / \mathrm{Fe}_{\text {tot }}$ ratios are propagated from those reported by Lecuyer and Ricard (1999).

Sulfur Measurements of sulfur contents of AOC are relatively sparse in the literature. However, detailed measurements (Alt, 1995) have been made for samples from Ocean Drilling Program hole 504B, near the Costa Rica rift, which penetrates $1700 \mathrm{~m}$ of oceanic basement, and hole $735 \mathrm{~B}$, which penetrates gabbroic ocean crust. The primary magmatic sulfur content at hole 504B is 0.096 wt\% sulfur, consistent with measured primary sulfur contents in MORB of between 0.064 and $0.18 \mathrm{wt} \%$. Subsequent seawater alteration is highly spatially heterogeneous. Honnorez (2003) records sporadic anhydrite and common pyrite as secondary minerals throughout the volcanic and sheeted dykes section of hole 504B. There is a continuum between the bulk of ocean crust, which is less altered, the 'ocean floor metamorphism' of Honnorez (2003), with the 504B and $735 \mathrm{~B}$ cores taken as the type example, to the extreme hydrothermal alteration induced by intense hydrothermal circulation in locations such as the TAG mound, where basalts are almost completely replaced by quartz-paragonitepyrite assemblages.

Alt (1995) present sufficient data to allow a post-alteration weighted average $\mathrm{S}$ content of $0.0716 \mathrm{wt} \%$ to be calculated for hole $504 \mathrm{~B}$. $1 \%$ of this sulfur was held in anhydrite, and $99 \%$ in pyrite. This distribution is incompatible with the large proportion of sulfur lost during hydrothermal circulation of seawater at mid-ocean ridges (Alt, 2003), which is assumed to be precipitated as anhydrite. This apparent contradiction can be explained by the retrograde solubility of anhydrite. The solubility of this mineral increases as temperature decreases, so it has been proposed (Alt, 1995; Alt, 2003) that anyhdrite precipitated in MOR hydrothermal circulation cells redissolves on cooling. Alternatively, hole 504B may be unrepresentative - the sheeted dyke complex exposed within the 
Macquarie Island ophiolite contains intense gypsum veining, where gypsum is after anyhdrite, though exposures are insufficient to quantify sulfur addition satisfactorily.

Here, we take the Alt (1995) weighted average value of $0.07 \mathrm{wt} \%$ for the $\mathrm{S}^{-}$content of AOC. The $\mathrm{S}^{6+}$ content, is taken to be half way between the Alt (1995) value of $0.0007 \mathrm{wt} \%$ from 504B and the maximum value of $0.072 \mathrm{wt} \%$, which is consistent with the observed sulfate losses from seawater at mid-ocean ridges documented by Alt (2003). Uncertainties are taken to be $20 \%$ on the $\mathrm{S}^{-}$ content, and $50 \%$ on the $\mathrm{S}^{6+}$ content. These assumptions result in calculated sulfur subduction fluxes of $1.01 \pm 0.28 \times 10^{12}$ moles year $^{-1}$ for $\mathrm{S}^{-}$and $0.51 \pm$ $0.28 \times 10^{12}$ moles year $^{-1}$ for $\mathrm{S}^{6+}$.

\subsubsection{Mantle Lithosphere}

Subduction of unserpentinised mantle lithosphere has no net effect on the redox budget of the exosphere or the mantle, so only fluxes that relate to serpentinised material need to be estimated. However, it is very difficult to constrain the rate of subduction of serpentinised mantle lithosphere, because of the heterogeneous nature of serpentinisation. Serpentinisation is known to occur at transform faults (e.g. Mevel, 2001), fracture zones, along slow-spreading mid-ocean ridges (e.g. Cannat, 1996), and at passive margins (e.g. Skelton et al. 2005). Estimates of the volume percentage of serpentinised lithosphere vary substantially. Carlson (2001) examine seismic evidence from the Atlantic Ocean crust and state that serpentinised material cannot make up more than $5 \%$ of the lower ocean crust, though higher values in the lower velocity zone could bring the average to around 6\%. Mevel (2003) discuss serpentinisation at slowspreading and ultra-slow spreading ridges. These workers summarise evidence consistent with highly serpentinised peridotite $(>70 \%)$ in regions of ridge with low magma production. Hacker et al. (2003) show that seismic velocities in the low velocity zone are consistent with around $20 \%$ serpentinisation, while examination of the results of Skelton et al. (2005) reveals that the seismic profile of the Iberian Margin is consistent with $28 \%$ serpentinisation of an $8 \mathrm{~km}$ section of 
initially peridotitic crust.

Serpentinisation is also thought to occur as a result of lithosphere bending and subsequent fluid infiltration as the lithosphere enters subduction zones. Ranero and Salleres (2004) use seismic evidence to estimate that the lithosphere entering the North Chile trench is $17 \%$ serpentinised to a depth of $20 \mathrm{~km}$. A more conservative estimate is provided by Rupke et al. (2004), who assume that a $10 \mathrm{~km}$ thick layer of the mantle lithosphere is $5 \%$ serpentinised; this estimate is broadly consistent with that of Carlson (2001). An even higher estimate is provided by Gorman et al. (2006), who model subduction zone processes assuming $20 \mathrm{~km}$ of $20 \%$ serpentinised mantle. If the two most extreme estimates are treated as brackets, and the thickness is taken to be the product of the percentage serpentinisation and the total thickness, then the average thickness of serpentinised peridotite entering the Earth's subduction zone is between 0.5 and $3.4 \mathrm{~km}$. The volume of subducted serpentinised peridotite, calculated assuming a subducted area of $2.45 \mathrm{~km}^{2}$ year ${ }^{-1}$, after Jarrard (2003), is then 1.23 to $8.33 \mathrm{~km}^{3}$ year ${ }^{-1}$, equivalent to a mass flux of 3.4 to $23.3 \times 10^{15}$ grams year ${ }^{-1}$ for a density of $2800 \mathrm{~kg} \mathrm{~m}^{-3}$. Here we take the average of the two estimates of $13 \times 10^{15}$ grams year $^{-1}$, with an uncertainty of $10 \times 10^{15}$ grams year $^{-1}$.

Estimates of Fe, $\mathrm{C}$ and $\mathrm{S}$ contents of serpentinised peridotite are relatively rare, though estimates for one or more of these parameters are presented by Alt and Shanks (2003); Paulick et al. (2006); Hattori and Guillot (2007) and Vils et al. (2008). Additionally, it is difficult to obtain good constraints on the spatial heterogeneity of data because of the limited diameter of drill core. Ideally, it would be possible to use partially serpentinised ophiolites as analogues for partially serpentinised mantle lithosphere, because easy access is possible to large areal extent of outcrop. However, it is not necessarily the case that ophiolite-hosted serpentinised peridotites are a satisfactory analogue for those found in subducting slabs. For this reason we present here new measurements of $\mathrm{Fe}, \mathrm{C}$ and $\mathrm{S}$ contents for serpentinised peridotite material from the New Caledonia ophiolite and from ODP leg 209, holes 1268 and 1274. The data allows 
us to (1) compare the characteristics of the two different types of ultramafic material and (2) to gain additional estimates of the carbon, iron, and sulfur contents of serpentinised peridotite.

Geological Settings New Caledonia Samples were collected from the ophiolite that forms the Massif du Sud in New Caledonia (Prinzhofer et al. 1980; Marchesi et al. 2009). The Massif du Sud is constructed from supra-arc mantle (DuPuy et al., 1981) that was thrust onto pre-existing continental basement of New Caledonia during the Eocene (Aitchison et al. 1995). The ophiolite consists of mostly harzburgitic peridotite with rare gabbro pods; structurally higher units such as pillow basalts and sheeted dykes are absent. Much of the ophiolite is heavily lateritised, but unweathered material has been exposed by human activities in some areas.

Samples were collected from three localities with varying degrees of serpentinisation from the relatively unweathered exposures in the spillway of the Yate Dam. Samples NC07-01 to 04 were collected from outcrop that was heavily veined and serpentinised, and located within metres of a highly altered thrust fault at $166^{\circ} 40.051^{\prime} \mathrm{E}, 022^{\circ} 08.593^{\prime}$ S. Samples NC07-05 to 07 and NC07-10 were taken from an outcrop with an intermediate exent of alteration at $166^{\circ} 53.072^{\prime}$ E, 022 $08.863^{\prime}$ S. Samples NC07-08 and 09 were taken from the margin of an orthopyroxene vein in harzburgite at this intermediate outcrop. Samples NC0711 to 14 were taken from relatively fresh outcrop at $166^{\circ} 52.985^{\prime} \mathrm{E}, 022^{\circ} 08.933^{\prime}$ S. At this outcrop, olivine and orthopyroxene grains could still be distinguished in some areas.

ODP Leg 209 ODP Leg 209 drilled abyssal peridotite from the $15^{\circ} 20^{\prime} \mathrm{N}$ area of the Mid-Atlantic ridge. These peridotites are sections of the upper mantle, which are exposed on the seafloor by tectonic faulting associated with crustal thinning and extension. In this area, peridotite and gabbroic rocks are exposed on both sides of the slow-spreading Mid-Atlantic Ridge in the vicinity of the $15^{\circ} 20^{\prime} \mathrm{N}$ fracture zones. Evidence for seawater-peridotite interactions are provided by the high temperature hydrothermal discharges of the Logatchev black smoker field (e.g. Charlou et al., 1998). Full details of lithologies and the 
geochemistry of the rocks are provided by Paulick et al. (2006) and Vils et al. (2008).

For the purposes of this study, we obtained samples from two drillholes. Hole 1268A (samples 69321-69332) samples talc- and serpentine-altered harzburgite and dunite, with pyrite, which is relatively rare in samples from the other ODP 209 drillholes. Material from this hole is highly altered and alteration minerals form over $90 \%$ of the mineral assemblage in most samples. Hole 1274A (samples 69427-69499) samples the least altered material found, and alteration minerals comprise between 60 to $95 \%$ of the mineral assemblage. A detailed description of the mineralogy and geochemistry of samples from these holes is provided by Paulick et al. (2006).

Methods Polished thin sections were made from selected samples from both sample suites and subjected to petrological examination. Major element composition, plus selected trace elements of the rocks was determined by fusion with lithium tetraborate and X-ray Fluorescence (XRF) analysis. Carbon and sulfur contents were determined by LECO analysis. Total iron was determined by $\mathrm{XRF}$, and the $\mathrm{FeO}$ content was determined by titration against ceric sulfate. It should be noted that this titration will also oxidise reduced sulfur, so values are overestimated for sulfur-bearing samples. The overestimation was calculated to be less than $1 \%$ for the New Caledonia samples, and less than $5 \%$ for all but four of the ODP 209 samples, but reaches $30 \%$ for sample 69332, which has the highest sulfur content. All analysis was performed by the commercial Genalysis laboratory in Perth, Australia.

\section{Tables 1, 2 and 3 near here}

\section{Figure 2 near here}

Results The primary assemblage at the ODP 209 site and in the New Caledonia ultramafics is that of harzburgite, with clinopyroxene generally absent. Chromite is present in most of the New Caledonia samples, but is less common in the ODP 209 samples.

Samples from both localities are heavily serpentinised with primary minerals forming less than $40 \%$ of the assemblage in all cases. Olivine is almost 
completely destroyed in all of the ODP 209 samples, whereas orthopyroxene is more resistant and is present in variously altered states in most samples. The New Caledonia samples are slightly less altered, with some primary olivine remaining in some cases. The most common alteration mineral is serpentine. It is present as an hour-glass textured replacement of olivine, and in multiple generations of veins that cross-cut all the samples. Magnetite is also present in most samples, but is volumetrically more abundant in the New Caledonia samples where it forms rims on serpentine, and forms part of the vein mineral assemblage. Talc and carbonate veins are sporadically present in the ODP 209 samples but are rare in the New Caledonia samples. Where talc and carbonate are found together, the carbonate veins and alteration postdate the talc veins. Pyrite is present in a small number of samples from both localities, anhydrite and pyrrhotite were not observed, but preparation techniques would probably have resulted in anhydrite dissolution if it were present.

The major element geochemistry of both sample suites (Table 1) is consistent with a depleted mantle origin for the harzburgites. The New Caledonia samples are slightly more depleted than the ODP 209 samples, as shown by the lower $\mathrm{Al}_{2} \mathrm{O}_{3}$ and $\mathrm{TiO}_{2}$ and higher $\mathrm{MgO}$ contents for the New Caledonia samples (Figure 2a). The New Caledonia samples also show higher $\mathrm{Cr}$ and $\mathrm{Ni}$ and lower Ti (Table 2), consistent with a greater degree of depletion. The LOI (Loss on Ignition) is a proxy for serpentinisation, as the primary assemblage is assumed to be effectively anyhdrous; inspection of the results for this parameter (Figure 2b) show that the New Caledonia samples are generally less altered than the ODP 209 samples, consistent with the petrological observations. Pure magnesian serpentine of the formula $\mathrm{Mg}_{3} \mathrm{Si}_{2} \mathrm{O}_{5}(\mathrm{OH})_{4}$ has a $\mathrm{H}_{2} \mathrm{O}$ content of $13.04 \mathrm{wt} \%$, so the more water-rich values obtained for some samples from both sample sites indicates the presence of other hydrated minerals. Brucite $\left(\mathrm{Mg}(\mathrm{OH})_{2}\right)$ is $31 \mathrm{wt} \%$ water and is common as an alteration product of olivine (Paulick et al., 2006; Frost and Beard, 2007) so it is likely that fine-grained brucite not recognised by optical microscopy is also present.

The ODP 209 rocks, in addition to the higher degree of alteration, also 
exhibit higher sulfur contents (Figure $2 \mathrm{~b}$ ), $\mathrm{Fe}^{3+} / \mathrm{Fe}_{\text {tot }}$ ratios (Figure $2 \mathrm{c}$ ), and higher concentrations of carbon (Figure 2d), than the New Caledonia samples. There is broad continuity between the two sample sets, although the most sulfurand carbon-rich samples from ODP $209(\mathrm{~S}>0.2 \mathrm{wt} \%, \mathrm{C}>0.5 \mathrm{wt} \%)$ are outliers to the broad trend defined by the remaining samples. Redox budgets for the two sample suites are also broadly similar, with apparent continuity between the New Caledonia and the majority of the ODP 209 samples (Figure 2e,f). The difference between the two data sets is small because slightly lower iron contents in the ODP 209 sample suite offsets the slightly higher $\mathrm{Fe}^{3+} / \mathrm{Fe}_{\text {tot }}$ for this suite.

To conclude, the ODP and New Caledonia samples are different with respect to the degree of serpentinisation, but petrological and geochemical evidence suggests that the serpentinisation process itself has proceeded in a similar way and with similar chemical consequences. It is therefore viable to use the New Caledonia rocks, with caution, as an analogue for the earlier stages of serpentinisation undergone by abyssal peridotites.

Carbon Measurements of the carbon content of serpentinised peridotite are provided by Paulick et al. (2006) for 5 samples from four different drillholes sampled by ODP 209. The value obtained for carbon as $\mathrm{CO}_{2}$, by a similar method to that used here, is $0.05 \pm 0.03 \mathrm{wt} \%$. This is comparable to values obtained for the New Caledonia samples of $0.13 \pm 0.08$ wt $\%(n=13)$ and somewhat lower than values obtained for ODP 209 samples by this study, of 0.45 $\pm 0.56 \mathrm{wt} \%(n=18)$, which reflects the inclusion of a small number of samples that contain a large proportion of carbonate veins. A weighted combination of all analyses gives a value of $0.28 \pm 0.8 \mathrm{wt} \% \mathrm{C}$, and this value is used here. Carbon is assumed to be present as carbonate, as other forms of carbon were not observed. The mass flux of $\mathrm{C}^{4+}$ in serpentinised peridotite is therefore 3.03 $\pm 3.83 \times 10^{12}$ moles year $^{-1}$.

Iron Measurements of $\mathrm{FeO}$ and $\mathrm{Fe}_{2} \mathrm{O}_{3}$ contents of 13 serpentinised peridotite samples from ODP 209 are provided by Paulick et al. (2006). Values of $6.88 \pm 0.95 \mathrm{wt} \%$ for total $\mathrm{Fe}$ as $\mathrm{FeO}$, and $0.63 \pm 0.07$ for $\mathrm{Fe}^{3+} / \mathrm{Fe}_{\text {tot }}$ were 
obtained. These values are comparable to values for the New Caledonia sample suite $(n=13)$ of $7.14 \pm 0.34 \mathrm{wt} \%$ for total $\mathrm{Fe}$ as FeO, and $0.5 \pm 0.13$ for $\mathrm{Fe}^{3+} / \mathrm{Fe}_{\text {tot }}$, and values for the ODP sample suite of $6.46 \pm 0.37 \mathrm{wt} \%$ for total $\mathrm{Fe}$ as $\mathrm{FeO}$, and $0.52 \pm 0.08$ for $\mathrm{Fe}^{3+} / \mathrm{Fe}_{\text {tot }}$. These values are within uncertainty of each other so the weighted average was taken, which gives a $\mathrm{Fe}^{2+}$ content of 2.39 $\pm 0.4 \mathrm{wt} \%$ and a $\mathrm{Fe}^{3+}$ content of $2.88 \pm 0.4 \mathrm{wt} \%$. The mass flux of $\mathrm{Fe}^{2+}$ and $\mathrm{Fe}^{3+}$ in serpentinised peridotite are therefore $5.56 \pm 4.38 \times 10^{12}$ moles year $^{-1}$ and $6.70 \pm 5.24 \times 10^{12}$ moles year ${ }^{-1}$ respectively. The large uncertainties on the fluxes are mainly derived from the uncertainties on the volume of subducted serpentinised mantle lithosphere.

Sulfur Unaltered peridotite contains, on average, $0.025 \mathrm{wt} \%$ sulfur. Alt et al. (2007) present measured sulfur contents for peridotites and gabbros from ODP site 209 , at the $15^{\circ} 20^{\prime} \mathrm{N}$ fracture zone on the Mid-Atlantic Ridge. Average acid volatile sulfur contents, which is taken to reflect the contribution from $\mathrm{S}^{2-}$-bearing minerals such as pyrrhotite was $0.041 \pm 0.055 \mathrm{wt} \% \mathrm{~S}(n=27)$, with a range of 0 to $0.21 \mathrm{wt} \% \mathrm{~S}$. The average chromium-reduced sulfide, which is taken to represent pyrite $\left(\mathrm{S}^{-}\right)$was $0.048 \pm 0.14 \mathrm{wt} \% \mathrm{~S}(n=28)$, with a range of 0 to $0.73 \mathrm{wt} \% \mathrm{~S}$. The average sulfate sulfur content was $0.078 \pm 0.073 \mathrm{wt} \%$ $\mathrm{S}(n=36)$, with a range of 0.011 to $0.420 \mathrm{wt} \% \mathrm{~S}$. The large ranges indicate the spatially heterogeneous nature of serpentinising reactions. Sulfur was assumed to be derived from either the primary magmatic source or microbial reduction of seawater. Additional sulfur analyses, from ODP leg 209 (Paulick et al., 2006; Vils et al., 2008; this study), serpentinised peridotites from mud volcanoes in the Izu-Bonin Forearc (Alt and Shanks, 2006), serpentinised peridotites from the MARK fracture zone sampled on ODP leg 125 (Alt and Shanks, 2003), and from New Caledonia (this study), are summarised in Table 3. Values are highly heterogeneous. Values for the New Caledonia and Izu-Bonin forearc sites are lower than those from the MAR fracture zone sites, which may reflect that the former are mantle wedge serpentinites that may have experienced less direct seawater interaction than the MAR fracture zone samples. The values from Alt et al. (2007) are preferred for this study, because of the detail provided 
on speciation, and because they are known to involve abyssal peridotites. The mass flux of $\mathrm{S}^{2-}, \mathrm{S}^{1-}$ and $\mathrm{S}^{6+}$ in serpentinised peridotite are therefore $0.16 \pm$ $0.24 \times 10^{12}$ moles year $^{-1}, 0.2 \pm 0.59 \times 10^{12}$ moles year $^{-1}$ and $0.33 \pm 0.38 \times 10^{12}$ moles year ${ }^{-1}$ respectively.

\subsection{Output Fluxes}

\subsubsection{Igneous rocks}

The flux of igneous rocks from subduction-related magmatism is taken from the work of DePaolo (1983) on the growth of continents, and includes plutonic material. DePaolo's estimate is of $2.5 \pm 0.4 \mathrm{~km}^{3}$ year ${ }^{-1}$, which for a density of $3000 \mathrm{~kg} \mathrm{~m}^{-3}$, gives a mass flux of $7.5 \pm 1.2 \times 10^{15}$ grams year $^{-1}$.

Carbon Wysoczanski et al. (2006) measured volatile contents of quenched glasses from pillow-lava rims in the Kermadec Arc. Carbon contents are generally low, at $0.0007 \pm 0.0003 \mathrm{wt} \%(n=11)$, and always less than $0.0016 \mathrm{wt} \%$ in glasses, although a content of 0.018 wt\% was measured in a single melt inclusion. Wallace (2005) presents a summary of $\mathrm{CO}_{2}$ contents from a range of arc and back-arc magmas, and concentrations are generally less than $0.1 \mathrm{wt} \%$, though maximum concentrations of 0.1 and $0.21 \mathrm{wt} \%$ are recorded in melt inclusions from Cerro Negro, Nicaragua, and Central Mexico, respectively. Carbon dioxide is quite insoluble in silicate melts (e.g. Dixon and Stolper, 1995) so it is reasonable to assume that most of the carbon degases, and that this degassed carbon is included in the arc volcanic gases contribution to the budget. Here, we take the average of the Wysoczanski et al. (2006) measurements of 0.0007 $\pm 0.0003 \mathrm{wt} \%$. The redox state of the arc lavas is consistent with carbon in the +4 valence state so this estimate implies a $\mathrm{C}^{4+}$ flux of $0.0044 \pm 0.002 \times 10^{12}$ moles year ${ }^{-1}$.

Iron Lecuyer and Ricard (1999) measured the average $\mathrm{Fe}^{3+} / \mathrm{Fe}_{\text {tot }}$ in arc lavas to be $0.41 \pm 0.17$, with an average iron content of $7.53 \mathrm{wt} \%(n=99)$. Note that this estimate excludes the effects of degassing-related oxidation. Kelley and Cottrell (2009) measure $\mathrm{Fe}^{3+} / \mathrm{Fe}_{\text {tot }}$ in a selection of arc-lava hosted olivine melt inclusions, and obtain a value for $\mathrm{Fe}^{3+} / \mathrm{Fe}_{\text {tot }}$ of $0.21 \pm 0.05$, with an average total 
$\mathrm{FeO}+\mathrm{Fe}_{2} \mathrm{O}_{3}$ of $10.34 \pm 2.39$ wt $\%$. However, their values may be skewed to high iron values by the use of olivine-hosted melt inclusions. There is no published data, to the author's knowledge, on $\mathrm{Fe}^{3+} / \mathrm{Fe}_{\text {tot }}$ ratios of intrusive igneous rocks associated with arc magmatism, so the composition is assumed to be the same as those for the arc extrusive rocks. A weighted average of the Kelley and Cottrell (2009) and Lecuyer and Ricard (1996) data gives concentrations of $4.6 \pm 1.4$ and $3.1 \pm 1.4 \mathrm{wt} \%$ and fluxes of $6.2 \pm 2.1$ and $4.2 \pm 2 \times 10^{12}$ moles year $^{-1}$ $\mathrm{Fe}^{2+}$ and $\mathrm{Fe}^{3+}$ respectively.

Sulfur Arc lavas commonly have low sulfur contents. Alt et al. (1993) record a range of 0.002 to 0.029 wt \%, with an average of $0.01 \mathrm{wt} \%$ in glasses from the Marianas Island Arc. Similarly, Wysoczanski et al. (2007) record concentrations of 0.03 to 0.07 wt\% from the Kermadec arc. The low sulfur contents have been attributed to a low sulfur content in the arc magma source (Alt et al., 1993), which is consistent with the low sulfur contents of wedge-derived serpentinite from seamounts in the Izu-Bonin arc (Alt and Shanks, 2006). Alternative, or complementary, reasons for the low sulfur contents are degassing (Wysoczanski et al., 2007) and the relatively low solubility of sulfur in silicate melts melts that originate from slightly oxidised mantle (e.g. Alt et al., 1993). Higher sulfur contents are recorded in the review of arc and back-arc basaltic magma volatile contents by Wallace (2005), who assumes a global average of 0.13 wt\% for arc basalt $\mathrm{S}$ content. Here, we take an intermediate value of $0.05 \pm 0.04 \mathrm{wt} \%$ sulfur for arc-related igneous rocks. Observed sulfur-bearing phases in arc-related igneous rocks are pyrite, pyrrhotite, and chalcopyrite (e.g. Wysoczanski et al. 2007). Primary sulfides occur in small quantities as inclusions in phenocrysts. Sulfides also occur in vesicles, so these grains are likely to be secondary, although the sulfur is probably derived from the magma. Here it is assumed that $\mathrm{S}^{-}$is the dominant valence. This estimate implies a $\mathrm{S}^{-}$flux of $0.12 \pm 0.1 \times 10^{12}$ moles year ${ }^{-1}$. 


\subsubsection{Volcanic Gases}

Fluxes of volcanic gases are heterogeneous and difficult to quantify, but their importance in exospheric element budgets and influence on the environment has motivated many studies of this topic. Estimates of fluxes tend to be made by measurement of gases at individual volcanoes, followed by extrapolation to global values with power law distribution expressions, and removal of mantle contributions via measurements of ${ }^{3} \mathrm{He}$ (e.g. Hilton et al. 2002).

Carbon Hilton et al. (2002) made an extensive compilation of the outputs of volatiles from arcs, which included outputs from 11 arc segments worldwide. The total flux of $\mathrm{CO}_{2}$ from arc volcanism is $1.62 \times 10^{12}$ moles year ${ }^{-1}$ (Hilton et al., 2002). ${ }^{3}$ He measurements have been used to estimate that about $13 \%$ of this carbon is from the mantle (Shaw et al., 2003) and the rest is recycled carbon from the subducting slab. This is consistent with estimates by previous authors that range between 0.3 and $3.1 \times 10^{12}$ moles year $^{-1}$ (Marty et al., 1989 and Sano and Williams, 1996, respectively).

A theoretical estimate for $\mathrm{CO}_{2}$ release from subducted ocean crust sections that includes serpentinised upper mantle, altered ocean crust, and sediments as a function of geothermal gradient is provided by Gorman et al. (2006). A combination of their model with the subduction zone data compilation of Jarrard (2003) gives a flux of $\mathrm{CO}_{2}$ into the sub-arc region of 0.3 to $9 \times 10^{12}$ moles year ${ }^{-1}$, with the higher end of the range preferred by the authors.

Here we take the estimate of Hilton et al. (2002), corrected to remove the $13 \%$ mantle contribution, to give a flux of $1.41 \times 10^{12}$ moles year $^{-1}$. The uncertainty of $20 \%$ is taken to be the same as the correction between global and observed fluxes.

Iron The iron content of volcanic gases is assumed to be negligible.

Sulphur Estimates of $\mathrm{SO}_{2}$ fluxes from arcs range from 0.16-0.32 x $10^{12}$ moles year $^{-1}$ (Hilton et al., 2002; Wallace, 2005). Reduced sulphur species are much less abundant than $\mathrm{SO}_{2}$. Here, we use the estimate of Hilton et al. (2002), which is based on a compilation of measurements of gases from 11 arc segments. 
These authors calculate a global $\mathrm{SO}_{2}$ volcanic flux of $0.32 \times 10^{12}$ moles year ${ }^{-1}$. An uncertainty is not provided by these authors, so a value of $20 \%$ of the total is assumed.

Hydrogen Hydrogen may contribute to the redox budget of subduction zones by its presence in volcanic gases. Here, we follow the approach of Waldbauer and Hayes, (2006), who assume that the ratio of hydrogen to water in volcanic gases is 0.01 (Giggenbach, 1992). This assumption permits calculation of the hydrogen flux from the arc magmatic water flux, which is estimated to be $17 \mathrm{x}$ $10^{12}$ moles year $^{-1}$ (Wallace, 2005). Thus, the hydrogen flux is $0.17 \times 10^{12}$ moles year $^{-1}$. No uncertainty is provided so a value of $20 \%$ of the total is assumed.

\subsubsection{Non volcanic fluid release}

Non volcanic fluid release occurs via fluids that escape through the accretionary wedge, and possibly, in the back-arc region, although this issue is controversial (e.g. Sano et al., 2001, discussion in Hilton et al., 2002). The magnitude of non-volcanic fluid release is difficult to constrain, because of the wide range of wedge geometries and characteristics, and the diffuse, sub-aerial nature of fluid release. However, the mass homogenisation of $\delta^{18} \mathrm{O}$ in accretionary wedge material (Bebout, 1995) suggests that the fluids are likely to be voluminous and $\mathrm{H}_{2} \mathrm{O}$-rich. The total flux of $\mathrm{H}_{2} \mathrm{O}$ into subduction zones is of the order of 1-2 x $10^{15}$ grams year $^{-1}$ (Rea and Ruff, 1996, and references therein; Jarrard, 2003). $60-70 \%$ of this water is structural water in low temperature diagenetic minerals, or pore-water in sediments or altered ocean crust (Jarrard, 2003), and is likely to be released at relatively shallow depths and to flux either up the slab/mantle interface (Jarrard, 2003) or upwards through the mantle and accretionary wedge (Mottl et al. 2004). The mass of water released in this way is likely to be around $1 \times 10^{15}$ grams year $^{-1}$, and the fluxes of solutes can be calculated if sufficient estimates of their concentrations are known. A separate contribution may be made by methane-rich fluids from mud volcanoes and seeps (e.g. Kopf, 2002).

Carbon The extent of to which $\mathrm{CO}_{2}$ and other C-bearing gases are emitted in 
non-volcanic settings is very poorly constrained and a wide range of estimates have been presented. Carbon is present as dissolved carbonate in seep fluids (e.g. Mottl et al. 2004), and as methane in mud volcanoes and seeps (e.g. Kopf, 2002; 2003; Milkov et al., 2003).

Hilton et al. (2002) use a mass balance approach, based on the assumption of steady state mantle carbon concentrations, to calculate a total fore-arc carbon flux of $0.4 \times 10^{12}$ moles year ${ }^{-1}$. Wallman (2001) gives a conservative estimate of the return of carbon to the exosphere via fluid venting in fore-arcs of $0.04 \mathrm{x}$ $10^{12}$ moles year ${ }^{-1}$, but the oxidation state of this carbon is not specified, and the contribution of back-arc degassing is omitted.

Jarrard (2003) combines the inferred flux of fore-arc fluids (around $1.4 \mathrm{x}$ $10^{15}$ grams year $\left.{ }^{-1}\right)$ with the calculated solubility of $\mathrm{CO}_{2}$ in fore-arc fluids $(0.02$ wt $\%$ ) to calculate a $\mathrm{CO}_{2}$ flux of about $0.2 \%$ of subducted $\mathrm{CO}_{2}$, or $6.6 \times 10^{9}$ moles year ${ }^{-1}$. Mottl et al. (2004) measure alkalinity in fluids from springs in the Marianas forearc region. Measured $\mathrm{CO}_{2}$ concentrations, which were corrected for carbonate precipitation were 20 - $60 \mathrm{mmol} \mathrm{kg}{ }^{-1}$. These values, coupled with a total reflux fluid volume of $1.4 \times 10^{12} \mathrm{~kg}$ year ${ }^{-1}$, imply a carbonate flux of $2.8-8.4 \times 10^{10}$ moles year ${ }^{-1}$, an order of magnitude higher than the Jarrard (2003) estimate. The higher estimate is preferred, because it is based on actual rather than theoretical calculated $\mathrm{CO}_{2}$ concentrations. Even higher estimates are provided by Gorman et al. (2006) who model $\mathrm{CO}_{2}$ release from subducted ocean crust sections that includes serpentinised upper mantle, altered ocean crust, and sediments as a function of geothermal gradient. A combination of their model with the subduction zone data compilation of Jarrard (2003) gives a flux of $\mathrm{CO}_{2}$ into the fore-arc region of $0.3-2.1 \times 10^{12}$ moles year ${ }^{-1}$, dependent on the geometry of fluid flow. These high values are not consistent with the restricted solubility of $\mathrm{CO}_{2}$ in fluids at the low temperatures and pressures found in fore-arc regions (Jarrard, 2003), unless phase separation and subsequent emission of gas-phase $\mathrm{CO}_{2}$ operate to increase the $\mathrm{CO}_{2}$ flux.

Estimates of carbon emitted as methane from mud-volcanoes and seeps vary widely, from $7 \times 10^{9}$ to $1 \times 10^{13}$ moles of methane year ${ }^{-1}$ (Kopf, 2002; 2003; 
Milkov et al., 2003). The earlier estimates are lower and may be discarded, as newly discovered mud volcanoes have augmented the fluxes, but the range of possible values is still large, at around $10^{11}-10^{13}$ moles year ${ }^{-1}$. Uncertainties are increased by the likely incomplete nature of the current data compilations, and the fact that the tectonic environment is not specified in many literature sources. However, it is suggested that the bulk of mud volcanism is caused by plate convergence, and the dewatering of fluid-saturated sediment (Kopf, 2003). The likely under-reporting of seeps cancels somewhat against the likely inclusion of non-subduction zone sources in some studies, although the extent of the compensation is unclear. Isotope evidence from Bebout (1995) suggest that less than $25 \%$ of subducted organic carbon devolatilises in the sub-arc region, which would provide a flux of less than $0.18 \times 10^{12}$ moles year $^{-1}$ if the value for organic carbon fluxes in Table 2 is correct.

Here, the estimate for $\mathrm{CO}_{2}$ flux based on the Mottl (2004) measurements, of $5.6 \times 10^{10}$ moles year ${ }^{-1}$ is used, with an uncertainty of $70 \%$ of the absolute value. A value of $10 \times 10^{12}$ moles year ${ }^{-1}$ for methane fluxes is used, again with with an uncertainty of $70 \%$ of the absolute value.

Iron The iron content of non-volcanic fluids is assumed to be negligible. This is valid so long as the fluids are relatively poor in chlorine, and is consistent with measured fore-arc fluid compositions (e.g. Mottl et al., 2004).

Sulphur Mottl et al. (2004) measure sulphate concentrations in fluids from springs in the Marianas forearc region. Values increase as the depth to the slab increases. Values, corrected for anyhdrite/gypsum precipitation and microbial

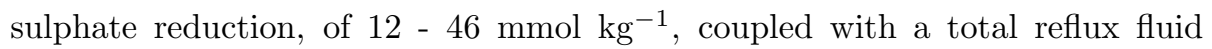
volume of $1.4 \times 10^{12} \mathrm{~kg}$ year ${ }^{-1}$, imply a sulphate flux of $1.7-6.4 \times 10^{10}$ moles year $^{-1}$. These values are much lower than the sulphur inputs to the subduction zone, and are likely to be controlled by anhydrite solubility in the mantle wedge, so the use of concentrations from a single subduction zone, while sub-optimal, is likely to provide a reasonable estimate of sulphur fluxes in these fluids. Here we take the mean value of $4.1 \times 10^{10}$ moles year $^{-1}$ from the Mottl et al. (2004) estimates, and use an arbitrary uncertainty of $70 \%$ of the absolute value. 


\subsubsection{Sub-arc and deep mantle}

Evidence of redistribution of redox-sensitive elements between the sub-arc and deep mantle is mostly qualitative, and uncertainties on quantitative estimates are so large as to make the estimates largely meaningless. For this reason we combine the sub-arc and deep mantle, and calculate element fluxes by difference. Nevertheless, it is useful to discuss possible differences between these two reservoirs.

Carbon The carbon content of non-arc related mantle is estimated at between 50 - 120 ppm (McDonough and Sun, 1995; Salters and Stracke, 2004). Estimates of carbon contents of sub-arc mantle are higher. Carbon contents presented here for the New Caledonia supra-subduction zone mantle are around 1,000 ppm, although the possibility of contributions from obduction and post-obduction processes for these samples cannot be excluded. Higher carbon contents in the sub-arc mantle are also supported by the results of Fischer and Marty (2005) who used $\mathrm{CO}_{2}$ :noble gas ratios to infer elevated $\mathrm{C}$ contents in sub-arc mantle, and the observations of Ducea et al. (2005), who noted primary calcite globules and veins in peridotite xenoliths from sub-Sierra Nevada mantle.

Connolly (2005) applies thermodynamic modelling techniques to investigate the release of carbon from subducting slabs, and concludes that the bulk of $\mathrm{CO}_{2}(>73 \%)$ is not released until below sub-arc depths. This value is broadly consistent (Fig. 3) with results of calculations made by those who study arc volcano gas outputs (e.g. Hilton et al. 2002), where isotope mass balance evidence has been used to propose constrain the proportion of emitted $\mathrm{CO}_{2}$ with a crustal source. The results are also consistent with the results of Dasgupta et al. (2004) who demonstrate experimentally that carbonate minerals are stable in carbonated eclogite down to pressures of $5-9 \mathrm{GPa}$, and the petrological observations of Bebout (1995) who find little evidence for significant removal of reduced carbon, at least in the upper parts of a subduction zone. If carbon is indeed retained, then much of the carbon in the slab is likely to proceed directly to the deep mantle. 
Iron There is little evidence of a systematic difference in iron concentrations between the sub-arc and non sub-arc mantle; compare McInnes (2001) with Salters and Stracke (2004). However, a number of studies suggest that the oxidation fugacity of iron is higher by one or two log units in sub-arc mantle relative to MOR-mantle (Balhaus et al., 1990; Wood et al., 1990; Brandon and Draper, 1996; Parkinson and Arculus, 1999; Kelley and Cottrell, 2009). Parkinson and Arculus (1999) calculate that the observed difference is consistent with the presence of 0.6 to $1 \mathrm{wt} \% \mathrm{Fe}_{2} \mathrm{O}_{3}$ in sub-arc mantle, whereas normal mantle has maybe $0.1-0.3 \mathrm{wt} \% \mathrm{Fe}_{2} \mathrm{O}_{3}$. Iron is unlikely to move directly from the slab to the sub-arc mantle because it is relatively insoluble (Eggler and Schneider, 1986) and see discussion below.

Sulphur The sulphur content of primitive and depleted mantle are given as 250 and $119 \pm 30$ ppm respectively (McDonough and Sun, 1995; Salters and Stracke, 2004). There is little evidence that sulfur concentrations in sub-arc mantle is higher than this. Serpentinised mantle material from seamounts has been metasomatised, with addition of sulphur by reduction of aqueous sulphate from slab sediments, but even after this metasomatism the sulphur content is generally less than 164 ppm (Alt and Shanks, 2006). McInnes et al. (2001) report $\mathrm{S}$ contents from harzburgites at the Lihir subduction zone, and these vary between 10 and $60 \mathrm{ppm}$. Similarly, S contents from the New Caledonia peridotites, which are thought to represent supra-subduction zone mantle, are no higher than the depleted mantle values (Table 1 ). It is therefore likely that sulfur is either recycled to the exosphere by reflux or melting processes, or is subducted to the deep mantle.

\section{Table 4, 5 near here}

\subsection{Flux estimates and uncertainties}

Element fluxes were calculated by multiplying reservoir fluxes by the concentration of the appropriate compositional variable (Table 5) for the different elemental redox states considered. Uncertainties were taken to be those discussed in the text, and were used to calculate a minimum and maximum flux of 
each redox state of each element (Table 5). If uncertainties were greater than $100 \%$, that is, the minimum flux would have been negative, then the minimum flux was set to zero. Where two parameters with uncertainties were combined, the uncertainty of the product was calculated assuming that the two parameters were uncorrelated. Such an approach is likely to be valid where one parameter is a mass flux, such as the rate of subduction of ocean crust, and the other is a compositional variable, such as the carbonate content of ocean crust sediments. Uncertainties can be considered as approximately $2 \sigma$ in that they cover most of the range of values measured or estimated, although too many of the uncertainties are defined arbitrarily for the value to be statistically meaningful. The fluxes of the individual redox states were then combined to give total element budgets for the subduction zones, with uncertainties propagated as before (Fig. 3 , Table 6).

Redox budget fluxes (Table 7) were then calculated using equation 1 for a mantle redox state and a crustal reference state. So, for example, the redox budget flux of $1 \times 10^{12}$ moles year ${ }^{-1}$ of $\mathrm{S}^{6+}$ relative to the $\mathrm{S}^{2-}$ mantle reference state is $8 \times 10^{12}$ moles year ${ }^{-1}$, because 8 moles of electrons are needed to reduce each mole of $\mathrm{S}^{6+}$ to $\mathrm{S}^{2-}$. The redox budget flux of $1 \times 10^{12}$ moles year ${ }^{-1}$ of $\mathrm{S}^{6+}$ relative to the $\mathrm{S}^{6+}$ crustal reference state is, on the other hand, zero, because the sulphur is already in the reference state. The mantle reference state is used to assess the effect of subduction on the mantle, and the crustal reference state is used to assess the effect of subduction on the exosphere.

The uncertainties were used in two different ways. First, the possible ranges of redox budgets were calculated, so the maximum effect of subduction on the mantle was estimated by combining the highest (most oxidising) redox budget fluxes for subduction input with the lowest redox budget fluxes (least oxidising) for the subduction outputs. The minimum effect on the mantle, the maximum effect on the crust and the minimum effect on the crust were calculated in similar ways. Element and redox budgets were used to calculate the net addition to the mantle, and the percentage recycled, for both the individual elements (Table 6) and for the overall redox budget (Table 8). 
Second, Monte Carlo calculations were undertaken, assuming (i) that uncertainties were normally distributed and (ii) that values were log-normally distributed. Monte Carlo calculations involve numerous repetitions of the redox budget calculation, with, in each repetition, values for each of the inputs and outputs taken randomly from a normal, in the case of (i), or a log-normal, in the case of (ii), distribution with the same mean and standard deviation as that inferred for each of the element fluxes from each of the inputs and outputs (Table 5). The mean and standard deviation redox budget flux was then calculated from the array of values created. These calculations were performed using Mathematica, and the results given are for 100000 iterations. Effectively identical answers were obtained for 1000 and 10000 iterations.

\section{Results}

\subsection{Element Budgets}

Element fluxes (Table 5, Table 6) indicate net addition of Fe $\left(55 \pm 13 \times 10^{12}\right.$ moles year $\left.{ }^{-1}\right), \mathrm{C}\left(4.6 \pm 4.0 \times 10^{12}\right.$ moles year $\left.^{-1}\right)$ and $\mathrm{S}\left(2.4 \pm 0.9 \times 10^{12}\right.$ moles year $^{-1}$ ) to the crust at subduction zones, even given the large uncertainties. The percentage of the elements recycled is $16 \pm 6 \%$ for Fe, $35 \pm 22 \%$ for $\mathrm{C}$, and $17 \pm 7 \%$ for $\mathrm{S}$. The extent to which these fluxes are balanced by known fluxes at MOR and ocean islands is discussed below.

AOC dominates the supply of Fe to subduction zones $\left(51 \pm 11 \times 10^{12}\right.$ moles year $\left.^{-1}\right)$, with about $20 \%$ supplied by the serpentinised lithosphere $\left(12 \pm 7 \times 10^{12}\right.$ moles year $\left.{ }^{-1}\right)$ and around $2 \%\left(1.2 \pm 0.2 \times 10^{12}\right.$ moles year $\left.^{-1}\right)$ by sediments. Arc rocks dominate the return of $\mathrm{Fe}$, because the Fe content of arc gases and non-volcanic fluid sources are assumed to be zero.

Serpentinised lithosphere is calculated to be biggest contributor of carbon to subduction zones $\left(3.0 \pm 3.8 \times 10^{12}\right.$ moles year $\left.^{-1}\right)$, although the contribution of $\mathrm{AOC}\left(2.2 \pm 0.6 \times 10^{12}\right.$ moles year $\left.^{-1}\right)$ is within the rather large uncertainty of the serpentinised lithosphere value. The sediment contribution $(1.9 \pm 0.7 \mathrm{x}$ $10^{12}$ moles year $^{-1}$ ) is also of the same order of magnitude. Return of carbon 
is controlled by the contribution of arc gases $\left(1.4 \pm 0.3 \times 10^{12}\right.$ moles year $\left.^{-1}\right)$, although the contribution of non-volcanic fluid sources is within the uncertainty of the arc gas contribution $\left(1.1 \pm 0.7 \times 10^{12}\right.$ moles year $\left.^{-1}\right)$.

$\mathrm{AOC}$ is the main contributor to the sulphur input budget of subduction zones $\left(1.5 \pm 0.4 \times 10^{12}\right.$ moles year $\left.{ }^{-1}\right)$, though contributions from serpentinised lithosphere $\left(0.7 \pm 0.8 \times 10^{12}\right.$ moles year $\left.{ }^{-1}\right)$ and sediments $\left(0.6 \pm 0.3 \times 10^{12}\right.$ moles year ${ }^{-1}$ ) are of the same order of magnitude. It is thus likely that different sulphur sources, and therefore different sulphur oxidation states, dominate the sulphur input at different subduction zones. Arc gases control the output of S from subduction zones $\left(0.3 \pm 0.06 \times 10^{12}\right.$ moles year $\left.^{-1}\right)$, with outputs about three times higher than that from the arc rocks $\left(0.12 \pm 0.10 \times 10^{12}\right.$ moles year $\left.^{-1}\right)$ , and eight times higher than the best estimate of the non-volcanic flux (0.04 \pm $0.03 \times 10^{12}$ moles year $\left.{ }^{-1}\right)$.

\section{Tables 6,7,8 near here Figure 3,4 near here}

\subsection{Redox Budget Fluxes}

\subsubsection{Relative to mantle reference state}

Both maximum and minimum oxidation redox budget fluxes (Table 8) for the mantle indicate that subduction increases the redox budget of the mantle over geological time, that is, a net increase in oxidising capacity results from subduction. The maximum value is $89 \times 10^{12}$ moles year $^{-1}$, and the minimum is $4.6 \times 10^{12}$ moles year ${ }^{-1}$. The wide range of estimates reflects the large uncertainties on many of the potentially important contributors to these redox budget fluxes. Monte-Carlo calculations for the mantle (Table 8) give a value of $46 \pm 12 \times 10^{12}$ moles year ${ }^{-1}$ for the assumption of a normal distribution, and $10^{13.5} \pm 0.3$ moles year ${ }^{-1}$ for the assumed log normal distribution. The range for the latter calculation is $46-59 \times 10^{12}$ moles year ${ }^{-1}$, which is consistent with the value of $46 \pm 12 \times 10^{12}$ moles year ${ }^{-1}$ for the normal distribution.

In the maximum mantle oxidation model, the largest contribution to the mantle oxidation is made by the subduction of serpentinised lithosphere $(46 \mathrm{x}$ $10^{12}$ moles year $\left.{ }^{-1}\right)$, in which carbon as carbonate is the main contributor $(27$ 
x $10^{12}$ moles year $\left.{ }^{-1}\right)$ with subsidiary contributions from $\mathrm{Fe}^{3+}\left(12 \times 10^{12}\right.$ moles year $\left.^{-1}\right)$ and $\mathrm{S}$ in pyrite and sulphate minerals $\left(6 \times 10^{12}\right.$ moles year $\left.^{-1}\right)$. A slightly smaller contribution is made by AOC $\left(36 \times 10^{12}\right.$ moles year $\left.^{-1}\right)$, within which $\mathrm{Fe}^{3+}$ dominates $\left(17 \times 10^{12}\right.$ moles year $\left.{ }^{-1}\right)$, with smaller contributions from $\mathrm{C}^{4+}$ $\left(11 \times 10^{12}\right.$ moles year $\left.^{-1}\right)$ and sulphate and sulphide minerals $\left(7 \times 10^{12}\right.$ moles year $\left.^{-1}\right)$. Sediments contribute about $10 \%$ of the input redox budget flux, in which $\mathrm{C}^{4+}$ dominates $\left(7 \times 10^{12}\right.$ moles year $\left.{ }^{-1}\right)$ with smaller contributions from $\mathrm{Fe}^{3+}\left(1.2 \times 10^{12}\right.$ moles year $\left.{ }^{-1}\right)$ and $\mathrm{S}^{-}\left(1 \times 10^{12}\right.$ moles year $\left.{ }^{-1}\right)$. The largest output contribution to the redox budget is made by non-volcanic fluids (-6.6 $\mathrm{x} 10^{12}$ moles year $\left.{ }^{-1}\right)$. This number is negative i.e. it causes a net increase of the mantle redox budget, because the carbon in methane is more reduced than the mantle reference state. The redox budget of the methane component is the largest contributor $\left(-6.8 \times 10^{12}\right.$ moles year $\left.^{-1}\right)$ to the redox budget flux attributable to non-volcanic fluid release. The non-volcanic fluid contribution is offset by the release of volcanic gases $\left(5.9 \times 10^{12}\right.$ moles year $\left.^{-1}\right)$ and arc igneous rocks $\left(2.2 \times 10^{12}\right.$ moles year $\left.{ }^{-1}\right)$. In the arc volcanic gases $\mathrm{C}^{4+}$ is the major contributor $\left(4.5 \times 10^{12}\right.$ moles year ${ }^{-1}$ ), with a smaller contribution from $\mathrm{S}$ in $\mathrm{SO}_{2}\left(1.5 \times 10^{12}\right.$ moles year $\left.{ }^{-1}\right)$ and a small decrease in the mantle redox budget due to the release of hydrogen $\left(-0.2 \times 10^{12}\right.$ moles year $\left.{ }^{-1}\right)$. In the arc rocks, $\mathrm{Fe}^{3+}$ provides the only significant contribution $\left(2.2 \times 10^{12}\right.$ moles year $\left.{ }^{-1}\right)$ with much smaller components provided by $\mathrm{C}^{4+}\left(0.01 \times 10^{12}\right.$ moles year $\left.^{-1}\right)$ and $\mathrm{S}^{-}$ in pyrite $\left(0.02 \times 10^{12}\right.$ moles year $\left.^{-1}\right)$.

In the minimum mantle oxidation model, AOC provided by far the largest input contribution to the redox budget flux $\left(15 \times 10^{12}\right.$ moles year $\left.{ }^{-1}\right)$. Serpentinised lithosphere provides only around $10 \%$ of this value $\left(1.5 \times 10^{12}\right.$ moles year $\left.{ }^{-1}\right)$, and the difference between this and the previous model reflects the wide range of uncertainties associated with the flux and composition of serpentinised lithosphere. The sediment contribution is around $20 \%$ of the AOC contribution $\left(3 \times 10^{12}\right.$ moles year $\left.{ }^{-1}\right)$. In terms of element contributions, the redox budget for AOC contains subequal contributions from $\mathrm{C}^{4+}\left(6 \times 10^{12}\right.$ moles year $\left.^{-1}\right)$ and $\mathrm{Fe}^{3+}\left(6 \times 10^{12}\right.$ moles year $\left.{ }^{-1}\right)$, with a factor of two smaller contribution from 
$\mathrm{S}$ in sulphide and sulphate $\left(3 \times 10^{12}\right.$ moles year $\left.^{-1}\right)$. In the serpentinised lithosphere, $\mathrm{Fe}^{3+}$ is the only contributor $\left(1.5 \times 10^{12}\right.$ moles year $\left.{ }^{-1}\right)$, because the $\mathrm{S}$ and $\mathrm{C}$ contributions are within uncertainty of zero. In the sediments, the $\mathrm{C}^{4+}$ component dominates $\left(7 \times 10^{12}\right.$ moles $\left._{\text {year }}{ }^{-1}\right)$, with smaller contributions form $\mathrm{Fe}^{3+}\left(1 \times 10^{12}\right.$ moles year $\left.{ }^{-1}\right)$ and $\mathrm{S}^{-}\left(0.3 \times 10^{12}\right.$ moles year $\left.^{-1}\right)$. In the output, a small degree of increase in the mantle oxidation budget is provided by methane in non-volcanic fluids $\left(-1.2 \times 10^{12}\right.$ moles year $\left.{ }^{-1}\right)$, but this is almost completely offset by carbonate $\mathrm{C}^{4+}$ and sulphate $\mathrm{S}^{6+}$ dissolved in the fluids with fluxes of $\left(0.4 \times 10^{12}\right.$ moles year $\left.{ }^{-1}\right)$ and $\left(0.6 \times 10^{12}\right.$ moles year $\left.^{-1}\right)$ respectively . Net decreases in the mantle redox budget are also due to the emission of arc gases $\left(9 \times 10^{12}\right.$ moles year $\left.{ }^{-1}\right)$ and arc rocks $\left(6 \times 10^{12}\right.$ moles year $\left.^{-1}\right) . \mathrm{C}^{4+}$ dominates the arc gas contribution $\left(7 \times 10^{12}\right.$ moles year $\left.{ }^{-1}\right)$, with a smaller contribution from $\mathrm{SO}_{2}\left(2 \times 10^{12}\right.$ moles year $\left.{ }^{-1}\right)$ and a slight negative effect from $\mathrm{H}_{2}$ release $\left(-0.1 \times 10^{12}\right.$ moles year $\left.{ }^{-1}\right)$. In arc rocks, the greatest contribution comes from $\mathrm{Fe}^{3+}\left(6 \times 10^{12}\right.$ moles year $\left.{ }^{-1}\right)$ with a smaller addition from $\mathrm{S}^{-}\left(0.2 \times 10^{12}\right.$ moles year $\left.^{-1}\right)$.

\subsubsection{Relative to crustal reference state}

Calculated changes in the redox budget of the exosphere due to subduction are positive, that is, subduction increases the oxidising capacity of the exosphere relative to the specified crustal reference state. This may seem counterintuitive, given that subduction also increases the redox budget of the mantle, but can be understood in the terms that much of the subducted material, such as the $\mathrm{Fe}^{2+}$ in the AOC for example, is reduced relative to the crustal reference state, so subduction of this material increases the redox budget of the exosphere. The heterogeneous nature of the exosphere means that large scale crustal reference states will never represent the individual reservoirs accurately, and that the figures presented cannot represent the true effect of subduction on the exosphere. However, the values can be used to gain an idea of the relative effects of the fluxes of the different components. For both maximum and minimum crustal oxidation models, the largest contributor to crustal oxidation is the AOC, with 


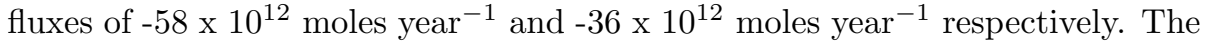
AOC budget is dominated by the contribution of $\mathrm{Fe}^{2+}$ of $-49 \times 10^{12}$ moles year ${ }^{-1}$ and $-31 \times 10^{12}$ moles year ${ }^{-1}$ for the maximum and minimum crustal oxidation respectively, with a smaller contribution from $\mathrm{S}^{-}$of $0.02 \times 10^{12}$ moles year ${ }^{-1}$ and $\left(0.21 \times 10^{12}\right.$ moles year ${ }^{-1}$ for maximum and minimum crustal oxidation respectively.

In the maximum crustal oxidation model, serpentinised lithosphere provides the next largest contribution $\left(-19 \times 10^{12}\right.$ moles year $\left.^{-1}\right)$, within which the largest component is $\mathrm{Fe}^{2+}\left(-10 \times 10^{12}\right.$ moles year $\left.{ }^{-1}\right)$, followed by $\mathrm{S}^{-}$and $\mathrm{S}^{2-}\left(-9 \times 10^{12}\right.$ moles year $\left.{ }^{-1}\right)$. Sediments provide the smallest contribution $\left(-11 \times 10^{12}\right.$ moles year $\left.^{-1}\right)$, in which $\mathrm{S}^{-}$in pyrite provides the largest component $\left(-6.7 \times 10^{12}\right.$ moles year $\left.^{-1}\right)$, followed by $\mathrm{C}^{0}\left(-4.4 \times 10^{12}\right.$ moles year $\left.{ }^{-1}\right)$, and a small $\mathrm{Fe}^{2+}$ component $\left(-0.3 \times 10^{12}\right.$ moles year $\left.{ }^{-1}\right)$. The largest output contributor in the maximum crustal oxidation model is the arc rocks $\left(-4.2 \times 10^{12}\right.$ moles year $\left.^{-1}\right)$, within which $\mathrm{Fe}^{2+}\left(-4.1 \times 10^{12}\right.$ moles year $\left.{ }^{-1}\right)$ makes the largest contribution, decreasing the exospheric redox budget relative to the crustal reference state. There is also a small $\mathrm{S}^{-}$contribution $\left(-0.1 \times 10^{12}\right.$ moles year $\left.{ }^{-1}\right)$. Small reductions to the exospheric redox budget relative to the crustal reference state are also made by the non-volanic fluid flux $\left(-2.4 \times 10^{12}\right.$ moles year $\left.{ }^{-1}\right)$ and arc gases $(-0.7 \times$ $10^{12}$ moles year $\left.{ }^{-1}\right)$. In the non-volcanic fluids, the only contributor is $\mathrm{C}^{4-}$ in methane. In the arc gases, $\mathrm{S}^{4+}$ in $\mathrm{SO}_{2}\left(-0.5 \times 10^{12}\right.$ moles year $\left.{ }^{-1}\right)$ and $\mathrm{H}^{0}(-0.2$ $\mathrm{x} 10^{12}$ moles year ${ }^{-1}$ ) in $\mathrm{H}_{2}$ both make small contributions.

In the minimum crustal oxidation model, sediments provide the second largest contribution next to $\operatorname{AOC}\left(-3.5 \times 10^{12}\right.$ moles year $\left.^{-1}\right)$, with contributions from $\mathrm{S}^{-}$in pyrite $\left(-2 \times 10^{12}\right.$ moles year $\left.{ }^{-1}\right), \mathrm{C}^{0}\left(-1.3 \times 10^{12}\right.$ moles year $\left.^{-1}\right)$, and $\mathrm{Fe}^{2+}\left(-0.2 \times 10^{12}\right.$ moles year $\left.{ }^{-1}\right)$. Serpentinised lithosphere provides only a small component $\left(-1.2 \times 10^{12}\right.$ moles year $\left.{ }^{-1}\right)$, in which the only contribution comes from $\mathrm{Fe}^{2+}$, because $\mathrm{C}$ and $\mathrm{S}$ are present in zero concentrations due to the large uncertainties. The largest output is, again, $\mathrm{C}^{4-}$ in methane in nonvolcanic fluids $\left(-13.6 \times 10^{12}\right.$ moles year $\left.{ }^{-1}\right)$. Smaller outputs come from arc rocks $\left(-9.8 \times 10^{12}\right.$ moles year $\left.{ }^{-1}\right)$ and arc gases $\left(-1 \times 10^{12}\right.$ moles year $\left.^{-1}\right)$. The arc rock 
redox budget flux comprises a large contribution from $\mathrm{Fe}^{2+}\left(-8.3 \times 10^{12}\right.$ moles year $\left.^{-1}\right)$ and a much smaller one from $\mathrm{S}^{-}\left(-1.5 \times 10^{12}\right.$ moles year $\left.^{-1}\right)$. The arc gas redox budget is made up of contributions from $\mathrm{S}^{4+}$ in $\mathrm{SO}_{2}\left(-0.8 \times 10^{12}\right.$ moles year $\left.{ }^{-1}\right)$ and $H^{0}\left(-0.2 \times 10^{12}\right.$ moles year $\left.{ }^{-1}\right)$.

To summarise, subduction increases the mantle redox budget. Major input contributions are made by AOC, and, potentially, by serpentinised lithosphere, although the latter flux is poorly constrained. Sediments provide a smaller (11$16 \%$ ) but significant contribution. Fe and $\mathrm{C}$ are large contributors to all fluxes, with $\mathrm{S}$ in a variety of redox states providing a small but significant component. Individual output fluxes are generally smaller than input fluxes, and the total is significantly less (Table 8).

The largest effect on the exospheric redox budget relative to the crustal reference state is made by subduction of $\mathrm{Fe}^{2+}$ in $\mathrm{AOC}$, with smaller but similar order of magnitude contributions made by subduction of reduced material in sediments and serpentinised lithosphere. This effect is offset by the release of non-volcanic fluids, arc gases and arc rocks, all of which are reduced relative to the crustal reference state.

\section{Discussion}

\subsection{Comparison with previous work}

The results indicate large imbalances in elemental and redox budgets, with fluxes from the exosphere to the subduction zone, sub-arc and deep mantle of Fe, C, S, and redox budget. These values can be compared with those obtained by previous work.

Lecuyer and Ricard (1999) estimated that $11.2 \times 10^{12}$ moles year $^{-1}$ of $\mathrm{Fe}^{3+}$ are transported into the mantle by subduction. This compares with a value for our study of $19.1 \pm 7.6 \times 10^{12}$ moles year $^{-1}$. The main reason that the value for this study is higher is that ferric iron in serpentinised lithosphere was not considered in the Lecuyer and Ricard study. 
Hayes and Waldbauer (2006) present a study that focusses on the exospheric redox budget, and do not present a full redox budget for subduction zones. However, they do present some estimates relevant to the study of subduction zone redox fluxes. They suggest that redox budget changes associated with organic carbon flux into the mantle are similar to redox budget changes induced by the emission of reduced gases at subduction zones. The implicit reference state for their calculations is $\mathrm{C}$ as $\mathrm{C}^{4+}$ and $\mathrm{S}$ as $\mathrm{S}^{2-}$. Using this reference state, the redox budget of the organic carbon that is added to subduction zones is -2.9 $\pm 1.6 \times 10^{12}$ moles year $^{-1}$, and the redox budget of the reduced arc gases is -1.9 $\pm 0.4 \times 10^{12}$ moles year $^{-1}$. These figures are within error of each other, so the values presented in Table 6 are consistent with those of Hayes and Waldbauer (2006).

\subsection{Balances against $M O R$ and $O I B$}

The net addition of Fe, C, S and redox budget must be balanced, to some extent, by outputs from plume and mid-ocean ridge (MOR) magmatism. Estimates for these fluxes were therefore made (Table 9). Iron contents for MOR rocks were taken from Lecuyer and Ricard (1999), assuming the $\mathrm{Fe}^{3+} / \mathrm{Fe}_{\text {tot }}$ measured for undegassed basaltic lavas by Christie et al. (1986). MOR $\mathrm{CO}_{2}$ contents were taken from the work of Saal et al. (2002), and carbon is assumed to be all $\mathrm{C}^{4+}$. S contents for MOR presented by Edmond et al. (1979), Wallace and Carmichael (1992) and Saal et al. (2002) are all similar, so a value of 0.09 $\pm 0.01 \mathrm{wt} \% \mathrm{~S}$ was taken for MOR rocks. Wallace and Carmichael (1992) measured sulphur valence in MOR basalts, and their value for $\mathrm{S}^{6+} / \mathrm{S}($ tot $)$ of 0.07 , with a large uncertainty of 0.07 , was taken here. The large uncertainty reflects the difficulty in the measurement of sulphur valence states by electron microprobe methods, as well as the inherent variability and relatively small sample set. The overall flux is set to be equal to the AOC subduction flux, since there is no good evidence that there is non-steady state with respect to the quantity of ocean crust, at least on long timescales. Iron contents and $\mathrm{Fe}^{3+} / \mathrm{Fe}_{\text {tot }}$ for plume rocks were taken from the compilation of Lecuyer and Ricard (1999). The $\mathrm{CO}_{2}$ 
content of plume-related igneous rocks was obtained by extrapolation from the estimate of a global $\mathrm{CO}_{2}$ flux from this source of $3 \times 10^{12}$ moles year ${ }^{-1}$ (Marty and Tolstikhin, 1998), and the estimate of the global flux of plume-related igneous rocks, which was taken to be $10 \%$ of the MOR flux, after Marty and Tolstikhin (1998). The S content of the OIB lavas was taken from the measurements of Gurenko and Schminke (2000), with information on valence states from Wallace and Carmichael (1992).

$\mathrm{Fe}, \mathrm{C}$, and $\mathrm{S}$ fluxes balance, within error, once the MOR and OIB fluxes are added to the subduction and arc outputs. The total MORB plus OIB output of $\mathrm{Fe}$ is $57 \pm 21 \times 10^{12}$ moles year $^{-1}$, which balances against the net subduction addition of $55 \pm 13 \times 10^{12}$ moles year $^{-1}$. Similarly, the MORB plus OIB output of $\mathrm{C}$ is $3.2 \pm 1.3 \times 10^{12}$ moles year $^{-1}$, which balances against the net subduction addition of $4.6 \pm 4 \times 10^{12}$ moles year $^{-1}$, and the MORB plus OIB output of $\mathrm{S}$ is $1.8 \pm 0.3 \times 10^{12}$ moles year $^{-1}$, which balances against the net subduction addition of $2.4 \pm 0.9 \times 10^{12}$ moles year ${ }^{-1}$. The MORB plus OIB budgets are systematically slightly smaller, though within error, of the net subduction budget.

\section{Table 9 near here Figure 5 near here}

Comparison of the redox budget fluxes, on the other hand, suggests that an imbalance exists. If the net subduction redox budget flux is taken to be halfway between the maximum and minimum mantle oxidation value, with an uncertainty that covers the range of estimates then a mean value is obtained that is a factor of 2.5 higher than the best estimate of the MORB plus OIB outputs. If the results of the Monte Carlo calculations with the normally distributed subduction zone inputs and outputs are used, then the subduction input flux is significantly larger $\left(46 \pm 12 \times 10^{12}\right.$ moles year $\left.^{-1}\right)$ than the MORB plus OIB output $\left(19 \pm 6 \times 10^{12}\right.$ moles year $\left.^{-1}\right)$. If the results of the Monte Carlo calculations with the log normal distributed subduction zone inputs and outputs are taken then the ranges are again outside of uncertainty, with a value of $46-58$ $\mathrm{x} 10^{12}$ moles year $^{-1}$ for the subduction zone input. To conclude, even though the extremities of the estimates overlap because of the large uncertainties, results of 
the Monte Carlo calculations suggest that the subduction redox budget flux is not balanced by the MOR and plume-related outputs, and that a net increase in mantle redox budget over geological time on the order of $10 \mathrm{~s} \times 10^{12}$ of moles year $^{-1}$ is implied.

\subsection{Spatial and temporal evolution of mantle redox budgets}

Results indicate that the redox budget of the mantle has increased with time, unless the minimum estimates of redox budget fluxes are taken. It is interesting to consider (a) what effect this increase in redox budget could have had on mantle $f_{\mathrm{O}_{2}}$ over geological time and (b) how the added redox budget might be distributed throughout the mantle. Clearly, the two questions are related; if added redox budget is localised then the increase of $f_{\mathrm{O}_{2}}$ in that area will be much bigger than if it were well mixed throughout the whole mantle.

An estimate of the relationship between upper mantle $f_{\mathrm{O}_{2}}$ and redox budget was made using pMELTS (Ghiorso et al., 2002). The bulk composition was assumed to be that of the depleted upper mantle presented by Salters and Stracke (2004), with an $\mathrm{H}_{2} \mathrm{O}$ content of $116 \mathrm{ppm}$ and a $\mathrm{CO}_{2}$ content of 50ppm. Calculations were made by setting $f_{\mathrm{O}_{2}}$ and equilibrating the model system at $1200^{\circ} \mathrm{C}$ and $1 \mathrm{GPa}$. This provided a calculated value for the wt $\% \mathrm{Fe}_{2} \mathrm{O}_{3}$, which was then converted to a specific redox budget $\left(\right.$ moles $\left.\mathrm{kg}^{-1}\right)$. Results were then fit to an arbitrary but appropriate function so that $\triangle \mathrm{QFM}$ could be calculated as a function of specific redox budget. It was assumed that $\mathrm{Fe}_{2} \mathrm{O}_{3}$ is the principle contributor to unaltered mantle redox budget; there is little evidence that $\mathrm{CO}_{2}$ or sulphate species are present in sufficient quantities to make a significant contribution. Values of $\mathrm{Fe}_{2} \mathrm{O}_{3}$ are sensitive to the assumed pressure and temperature, but the specified conditions were chosen because they are typical of the region of equilibration for melts for which redox conditions have been calculated (e.g. Parkinson and Arculus, 1999). $f_{\mathrm{O}_{2}}$ will vary as the mantle mixes through different pressure and temperature conditions, but redox budget will not, unless open system processes occur to change the composition of the system. 
$f_{\mathrm{O}_{2}}$ varies as a function of specific redox budget according to equation 2 :

$$
\Delta \mathrm{QFM}=4.77+1.61 \ln \overline{R B},
$$

where $\triangle$ QFM is $\log f \mathrm{O}_{2}-\log f \mathrm{O}_{2 \mathrm{QFM}}$, where QFM refers to the quartz, fayalite, magnetite buffer and $\overline{R B}$ is the specific redox budget in moles $\mathrm{kg}^{-1}$. This relationship is shown in Fig. 6, and is similar to that illustrated by Parkinson and Arculus (1999) for similar input values.

\section{Figure 6 near here}

The effect that added redox budget has on the mantle specific redox budget, and thus on $f_{\mathrm{O}_{2}}$ depends on volume within which the added redox budget mixes according to

$$
\overline{R B_{\mathrm{M}}}=\overline{R B_{\mathrm{M}, \text { init }}}+\int_{t}^{t=0} \frac{R \dot{B}_{\mathrm{M}} \partial t}{F M}
$$

where $R \dot{B}_{\mathrm{M}}$ is the redox budget flux relative to the mantle reference state, $t$ is time, $F$ is the fraction of mantle to which the redox budget is added, and $M$ is the mass of the mantle, which is assumed here to be $3.64 \times 10^{24} \mathrm{~kg}$. If $R \dot{B}_{\mathrm{M}}$ is constant then

$$
\overline{R B_{\mathrm{M}}}=\overline{R B_{\mathrm{M}, \text { init }}}+\frac{R \dot{B}_{\mathrm{M}} \Delta t}{F M}
$$

where $\Delta t$ is the time period of interest over which the addition of redox budget occured, in years.

Existing constraints on $F$ and temporal changes in $f_{\mathrm{O}_{2}}$ come from a variety of sources. Local highs in $f_{\mathrm{O}_{2}}$ in sub-arc mantle proposed by a number of workers (e.g. Wood et al., 1990; Parkinson and Arculus, 1999; Kelley and Cottrell, 2009) suggest that redox budget increases are localised in the mantle wedge, at least to some extent, although the results of Lee et al. (2005), based on V/Sc measurements, contradict this suggestion.

The results of work by Kump et al. (2001) and Holland (2002) call on changes in the oxidation state of the Earth's mantle during the Archean to explain the rise in atmospheric oxygen. However, Lee and Li (2004) present evidence based on $\mathrm{V} / \mathrm{Sc}$ systematics, that the $f_{\mathrm{O}_{2}}$ of MORB is not more than $0.3 \log _{10}$ units 
greater than it was in the Archean. This work is consistent with that of Delano (2001), who used whole-rock $\mathrm{Cr}$ and $\mathrm{V}$, and the Cr content of spinels, to obtain a similar result. If the mantle $f_{\mathrm{O}_{2}}$ is indeed relatively constant then increases in redox budget may be restricted to sub-arc mantle, which may then become cratonised and isolated, or to the deep parts of subduction zones which may also be isolated on long timescales. Alternatively, increases in redox budget may be simply too small to shift the mantle off its current $f_{\mathrm{O}_{2}}$ buffer once mixing has occurred. The timescale over which redox budget fluxes have been similar to those of the present day may be comparatively short. Subduction redox budget fluxes prior to $2.3 \mathrm{Ga}$, the time of the GOE (Great Oxidation Event), are likely to have been much lower, because seawater was most likely too reduced to create the carbonates, sulphates, and ferric iron that drive the increases in redox budgets proposed for the present day. However, serpentinisation reactions may still have created ferric iron in magnetite, so redox budget fluxes may still have been significant. Redox budget fluxes were probably also much reduced between the GOE and $550 \mathrm{Ma}$, when atmospheric oxygen levels are thought to have reached current values,

It is beyond the scope of this paper to investigate these issues via modelling, but first order constraints can be obtained from four end-member scenarios.

\section{Figure 7 near here}

First, the case where all redox budget is added to the sub-arc mantle is considered. This can be visualised as addition of the subduction flux to the sub-arc mantle over the timescale of subduction, followed by immobilisation of the oxidised sub-arc mantle by incorporation into the lithosphere. The volume of subduction zones is calculated to be the volume of a prism, 44,450 km in length (Jarrard, 2003) by $80 \mathrm{~km}$ deep by $100 \mathrm{~km}$ wide, which gives a volume of $1.78 \times 10^{17} \mathrm{~m}^{3}$. If the average density of this material is $3000 \mathrm{~kg} \mathrm{~m}^{-3}$ then the value of $F$ for a mantle mass of $3.64 \times 10^{24} \mathrm{~kg}$, is 0.00015 . The results of redox budget fluxes of $70,35,1,0.1$ and $0.01 \times 10^{12}$ moles year $^{-1-1}$ are shown in Fig. 7a. Note the log scale on the $x$ axis. The location of the grey box represents the range of $f_{\mathrm{O}_{2}}$ values calculated for the upper mantle by Lee 
and Li (2004), and its height indicates their estimate of the sensitivity of the technique. Mantle $f_{\mathrm{O}_{2}}$ that lie within the grey box are indistinguishable from unaltered material. It can be seen that redox budget changes on the order of those observed for subduction zones (e.g. Kelley and Cottrell, 2009), i.e. one to two $\log f_{\mathrm{O}_{2}}$ units, occur on the $1 \mathrm{Ma}$ to $10 \mathrm{Ma}$ timescale, even for redox budget fluxes as low as $1 \times 10^{12}$ moles year ${ }^{-1-1}$. Subduction that continued for longer than $100 \mathrm{Ma}$, if fluxes were high and no mixing between sub-arc and other mantle occurred, would increase $f_{\mathrm{O}_{2}}$ to values much higher than those observed. This is reasonable, fluxes into the sub-arc mantle are likely to be only a small fraction of the total (see below), and the assumption that sub-arc mantle associated with a subduction zone could fail to mix effectively with surrounding mantle breaks down on the 100 Ma timescale. Further, only the most long-lived subduction zones operate on 100 Ma timescales (e.g. Chiarenzelli et al., 2010).

The next case to be considered is addition of redox budget to the whole of the upper mantle, a scenario that would be physically represented by effective upper mantle mixing on the timescale of interest, but with restricted interchange between upper and lower mantle material. For an upper mantle with depth 660 $\mathrm{km}$, and density $3300 \mathrm{~kg} \mathrm{~m}^{-3}$, the mass fraction of the upper mantle relative to the whole mantle, $F$, is calculated to be 0.25 . The results of redox budget fluxes of 70,35 and $1 \times 10^{12}$ moles year ${ }^{-1}$ are shown in Fig. $7 \mathrm{~b}$. It can be seen that if redox budget fluxes are of the order of $10 \times 10^{12}$ moles year $^{-1}$ or higher, and if they are largely transferred to the upper mantle alone, then measurable differences in upper mantle redox state should occur on the $100 \mathrm{Ma}$ to $1 \mathrm{Ga}$ timescale.

The third end-member scenario is that of effective whole-mantle mixing on the timescale of interest, i.e. $F$ is equal to 1 . The results of redox budget fluxes of 70,35 , and $1 \times 10^{12}$ moles year $^{-1}$ are shown in Figs $7 \mathrm{c}$. It can be seen that measurable differences in mantle redox state would occur only after timescales on the order of several $100 \mathrm{Ma}$ to Ga. If redox budget fluxes increased significantly at $550 \mathrm{Ma}$, when atmospheric oxygen levels are thought to have reached current values, then the present day is likely to lie within the grey area of the plots. In 
this case changes in mantle redox state have not yet occurred, but would occur in the next Ga or so.

Clearly, instantaneous effective mixing within the chosen reservoir is an unrealistic assumption, so in the fourth end-member scenario a crude attempt was made to incorporate the effects of gradual mixing. $F$ was set to increase via

$$
F=0.00015+0.99985\left(1-\exp \left[\frac{-\Delta t}{e 10^{8}}\right]\right)
$$

which allows $\mathrm{F}$ to increase exponentially from the value for subduction zones (0.00015) to that for the whole mantle over about $1 \mathrm{Ga}$, a value based on the estimates of whole mantle mixing time in Hoffman and MacKenzie (1985). Results, for redox budget fluxes of 70, 35 and $1 \times 10^{12}$ moles year $^{-1}$ are shown in Fig 7 d. Mantle $f_{\mathrm{O}_{2}}$ increases to a level that might be recognisable only after over several hundred Ma, even for the highest redox budget fluxes. However significant changes would be expected in the future, on a Ga timescale.

\subsection{Mechanisms of redox budget transfer to the mantle wedge}

It is also necessary to consider the method by which redox budget might be transferred from the subducting slab to the sub-arc mantle. $\mathrm{Fe}^{3+}, \mathrm{S}^{6+}$, and $\mathrm{C}^{4+}$ are the potential transfer agents, but the potential of each is restricted by their solubility.

The solubility of $\mathrm{Fe}^{3+}$ in subduction zone fluids is not well known, but Wykes et al. (2008) present some measurements of Fe concentrations for fluids with an $X(\mathrm{NaCl})$ of 0.1 in equilibrium with hematite at $800^{\circ} \mathrm{C}$ and $1 \mathrm{GPa}$. The molality of $\mathrm{Fe}$ in these fluids is less than 0.01 , and this value is probably a maximum for subduction zone fluids, since solubility tends to decrease with decreasing temperature and salinity, and the values used for the experiments are at the upper limits of those applicable at subduction zones. If the solubility of $\mathrm{Fe}^{3+}$ is taken to be 0.01 molar, and the flux of water into the mantle wedge is taken to be $10^{11} \mathrm{~kg}_{\text {year }}{ }^{-1}$ (c.f. Bebout, 1995), then the flux of $\mathrm{Fe}^{3+}$ is of the order of $10^{9}$ moles year ${ }^{-1}$, which is three to four orders of magnitude lower than the 
available redox budget flux. It has been proposed that high salinity fluids and silica-rich melt-like fluids may carry this element more effectively (e.g. Kessel et al., 2005) but such chemical characteristics are inconsistent with the relatively low salinities and concentrations proposed for subduction zone fluids (Hermann et al., 2006), and the existence of the silica-rich melt-like fluids is still not proven. It is therefore likely that the Fe remains in the slab during subduction, although $\mathrm{Fe}^{3+}$ could oxidise other fluid components so that the redox budget of the slab is effectively fractionated into slab fluids which may enter the sub-arc mantle, and the possibility of its movement cannot be excluded.

The solubility of $\mathrm{CO}_{2}$ in aqueous solutions at sub-arc depth is restricted to 1-2 wt\% (e.g. Connolly, 2005) and experimental results (Yaxley and Brey, 2004) have shown that carbonate can be stable to pressures up to $3.5 \mathrm{GPa}$. $1 \mathrm{wt} \%$ $\mathrm{CO}_{2}$ in solution converts, for an assumed flux of water into the mantle wedge of $10^{11} \mathrm{~kg}$ year ${ }^{-1}$ to a $\mathrm{CO}_{2}$ flux of $2.3 \times 10^{10}$ moles year $^{-1}$, which, with the four electron conversion to the mantle reference state, gives a redox budget flux of around $10^{11}$ moles year ${ }^{-1}$. Such a flux is an order of magnitude smaller than the overall redox budget flux, but could induce sub-arc mantle oxidation on a suitably long timescale if the $\mathrm{CO}_{2}$ were to be reduced to graphite in the sub-arc mantle. However, this seems unlikely, as the $\mathrm{CO}_{2}$ output from arc volcanoes suggests that most of the $\mathrm{CO}_{2}$ added to the sub-arc mantle is immediately recycled to the atmosphere via volcanism.

Water has been proposed as a carrier for oxidation capacity (e.g. Brandon and Draper, 1996) but this is a very inefficient mechanism, as the solubility of $\mathrm{O}_{2}$ in water is very small, so the redox budget of such fluids is tiny (Frost and Ballhaus, 1998) even when the potential for oxygen release by water dissociation is considered.

Sulphur may also carry redox budget as suggested by Kelley and Cottrell (2009). Anyhdrite is soluble in geological fluids, and solubility is positively correlated with salinity (Newton and Manning, 2005). The eight electron difference between sulphate and the mantle reference state means that this element is an effective agent for changes in redox budget. If $10^{11} \mathrm{~kg} \mathrm{year}^{-1}$ of water fluxes 
through the mantle wedge, and anhydrite solubilities are 0.02 to 2 moles $\mathrm{kg}^{-1}$ (Newton and Manning, 2005) then the potential sulphate flux is $0.02-2 \times 10^{11}$ moles year ${ }^{-1}$, which is much less than the overall sulfur budget $\left(2-4 \times 10^{12}\right.$ moles year ${ }^{-1}$ (Table 6), and capable of carrying 0.016 to $1.6 \times 10^{12}$ moles year $^{-1}$. A redox budget flux of $1.6 \times 10^{12}$ moles year $^{-1}$ can cause a measurable difference in subduction zone $f_{\mathrm{O}_{2}}$ on a $3 \mathrm{Ma}$ timescale, and a $1-2 \log$ unit change in 10 Ma, so sulfur does provide a plausible transfer medium. The S content of arc magmas is generally relatively low, as discussed above, which could be taken to indicate that sulfur is not transferred to the sub-arc mantle. Alternatively, it can be also attributed to low $\mathrm{S}$ in the source zone, the relative insolubility of $\mathrm{S}$ in magmas at subduction zone redox conditions, or effective $\mathrm{S}$ degassing from magmas. A comparison between S contents in supra-subduction zone and typical mantle peridotites would be useful to help evaluate this possibility, but there is insufficient data for robust conclusions to be drawn.

\subsection{Further work}

It has been shown that subduction of oxidised material has the potential to oxidise sub-arc mantle on geological timescales, but the uncertainties are large. The implications of this possibility for the studies of temporal changes in the atmosphere, volcanism, ore deposit formation, and continental evolution are significant, so further work to better constrain the least well constrained parameters is justified. The largest uncertainties are introduced by the extent of serpentinisation of the lithospheric mantle. If this could be constrained, by a combination of seismic and geochemical techniques, then more reliable conclusions could be drawn. Additional restrictions are placed by the poorly known solubilities of many elements in slab-derived fluids. Substantial experimental work to determine the mobility of $\mathrm{Fe}, \mathrm{C}$ and $\mathrm{S}$ in these fluids is required.

\section{Conclusion}

Fe, $\mathrm{C}$ and $\mathrm{S}$ and redox budget fluxes have been calculated for subduction zones from literature data. The largest uncertainties on the subduction zone 
redox budget are associated with the input of partially serpentinised mantle lithosphere, so new measurements for the composition of this material from New Caledonia and ODP leg 209 were presented. These data indicate that ophiolitic material can, in some cases, be used as a proxy for partially serpentinised mantle lithosphere from other environments, though the extent of serpentinisation was different in the two cases.

Uncertainties on the calculations are large, but results indicate that $\mathrm{Fe}, \mathrm{C}$, $\mathrm{S}$ and redox budget are all added in significant quantities by subduction to the sub-arc and deep mantle. When other mantle outputs from MORB and plumerelated magmatism are considered, the imbalances in $\mathrm{Fe}, \mathrm{C}$ and $\mathrm{S}$ are accounted for, so cycling of these elements is within error of steady state on some geological timescale. Subduction zone redox budget inputs were not balanced by MORB and plume-related outputs, except for the most conservative estimates of redox budget influx.

The fate of the redox budget added at subduction zones is difficult to determine unambiguously. Some is almost certainly added to the sub-arc mantle, by transfer of dissolved sulphate, carbonate, and to a lesser extent, $\mathrm{Fe}^{3+}$ in aqueous fluids. This quantity is restricted by low solubilities of these elements to less than $2 \times 10^{12}$ moles year ${ }^{-1}$, which is a relatively low proportion of the added total. Nevertheless, such an addition is capable of producing the observed high $f_{\mathrm{O}_{2}}$ values above subduction zones on a Ma to $10 \mathrm{Ma}$ timescale. The bulk of the redox budget is likely to be carried to the deep mantle by the slab, where it will be mixed on long $(\mathrm{Ga})$ timescales into the bulk of the mantle. Such addition may not have affected the redox state of the mantle at this point in time, because oxidised material only began to be subducted in the current quantities at $550 \mathrm{Ma}$, although changes are anticipated on a Ga timescale.

\section{Acknowledgments}

IODP for provision of the Leg 209 samples. Curtin for a fellowship. Roger Powell, Bruce Yardley, Jim Mungall, Marlena Elburg, Ron Frost for helpful 
1318 discussions. 


\section{References}

Aitchison, J. C., Clarke, G. L., Meffre, S., Cluzel, D., 1995. Eocene ArcContinent Collision in New-Caledonia and Implications for Regional Southwest Pacific Tectonic Evolution. Geology 23: 161-164.

Alt, J. C., 1995. Sulfur isotopic profile through the oceanic-crust - sulfur mobility and seawater-crustal sulfur exchange during hydrothermal alteration. Geology 23: 585-588.

Alt, J. C., 2003. Hydrothermal fluxes at mid-ocean ridges and on ridge flanks. Compt. Rend. Geosc. 335: 853-864.

Alt, J. C., Shanks, W. C., 2003. Serpentinization of abyssal peridotites from the MARK area, Mid-Atlantic Ridge: Sulfur geochemistry and reaction modeling. Geochim. Cosmochim. Acta. 67: 641-653.

Alt, J. C., Shanks, W. C., 2006. Stable isotope compositions of serpentinite seamounts in the Mariana forearc: Serpentinization processes, fluid sources and sulfur metasomatism. E.P.S.L. 242: 272-285.

Alt, J. C., Shanks, W. C., Bach, W., Paulick, H., Garrido, C. J., Beaudoin, G., 2007. Hydrothermal alteration and microbial sulfate reduction in peridotite and gabbro exposed by detachment faulting at the Mid-Atlantic Ridge, 15 degrees $20^{\prime} \mathrm{N}$ (ODP Leg 209): A sulfur and oxygen isotope study. Geochem. Geophys. Geosys. 8.

Alt, J. C., Shanks, W. C., Jackson, M. C., 1993. Cycling of sulfur in subduction zones - the geochemistry of sulfur in the Mariana-Island Arc and Back-Arc Trough. E.P.S.L. 119: 477-494.

Alt, J. C., Teagle, D. A. H., 1999. The uptake of carbon during alteration of ocean crust. Geochim. Cosmochim. Acta. 63: 1527-1535.

Alt, J. C., Teagle, D. A. H., 2003. Hydrothermal alteration of upper oceanic crust formed at a fast-spreading ridge: mineral, chemical, and isotopic evidence from ODP Site 801. Chem. Geol. 201: 191-211. 
Ballhaus, C., Berry, R. F., Green, D. H., 1990. Oxygen fugacity controls in the Earths upper mantle. Nature 348: 437-440.

Bebout, G. E., 1995. The impact of subduction-zone metamorphism on mantleocean chemical cycling. Chem. Geol. 126: 191-218.

Berner, R. A., 2001. Modelling atmospheric $\mathrm{O}_{2}$ over Phanerozoic time. Geochim. Cosmochim. Acta. 65: 685-694.

Brandon, A. D., Draper, D. S., 1996. Constraints on the origin of the oxidation state of mantle overlying subduction zones: An example from Simcoe, Washington, USA. Geochim. Cosmochim. Acta. 60: 1739-1749.

Canfield, D. E., 2004. The evolution of the Earth surface sulfur reservoir. Am. J. Sci. 304: 839-861.

Cannat, M., 1996. How thick is the magmatic crust at slow spreading oceanic ridges? J. Geophys. Res: Solid Earth. 101: 2847-2857.

Carlson, R. L., 2001. The abundance of ultramafic rocks in Atlantic Ocean crust. Geophys. Journ. Int. 144: 37-48.

Charlou, J. L., Bougault, H., Appriou, P., Nelsen, T., Rona, P., 1991. Different Tdm/Ch4 Hydrothermal Plume Signatures - Tag Site at 26-Degrees-N and Serpentinized Ultrabasic Diapir at 15-Degrees-05'n on the Mid-Atlantic Ridge. Geochim. Cosmochim. Acta. 55: 3209-3222.

Charlou, J. L., Fouquet, Y., Bougault, H., Donval, J. P., Etoubleau, J., JeanBaptiste, P., Dapoigny, A., Appriou, P., Rona, P. A., 1998. Intense CH4 plumes generated by serpentinization of ultramafic rocks at the intersection of the 15 degrees $20^{\prime} \mathrm{N}$ fracture zone and the Mid-Atlantic Ridge. Geochim. Cosmochim. Acta. 62: 2323-2333.

Chester, R. 1990, Marine Geochemistry, Unwin Hyman, London, 698 pp., 
Chiarenzelli, J., Lupulescu, M., Cousens, B., Thern, E., Coffin, L., Regan, S., 2010. Enriched Grenvillian lithospheric mantle as a consequence of long-lived subduction beneath Laurentia. Geology 38: 151-154.

Connolly, J. A. D., 2005. Computation of phase equilibria by linear programming: A tool for geodynamic modeling and its application to subduction zone decarbonation. E.P.S.L. 236: 524-541.

Crisp, J. A., 1984. Rates of Magma Emplacement and Volcanic Output. J. Volc. Geotherm. Res. 20: 177-211.

Dasgupta, R., Hirschmann, M. M., Withers, A. C., 2004. Deep global cycling of carbon constrained by the solidus of anhydrous, carbonated eclogite under upper mantle conditions. E.P.S.L. 227: 73-85.

de Hoog, J. C. M., Hattori, K. H., Hoblitt, R. P., 2004. Oxidized sulfur-rich mafic magma at Mount Pinatubo, Philippines. Contrib. Mineral. Petrol. 146: $750-761$.

Delano, J. W., 2001. Redox history of the Earth's interior since similar to 3900 Ma: Implications for prebiotic molecules. Orig. Life. Ev. Bios. 31: 311-341.

Depaolo, D. J., 1983. The mean-life of continents - estimates of continent recycling rates from $\mathrm{Nd}$ and $\mathrm{Hf}$ isotopic data and implications for mantle structure. Geophys. Res. Lett. 10: 705-708.

Dixon, J. E., Stolper, E. M., 1995. An experimental study of water and carbon dioxide solubilities in mid-ocean ridge basaltic liquids .2. Applications to degassing. J. Pet. 36: 1633-1646.

Ducea, M. N., Saleeby, J., Morrison, J., Valencia, V. A., 2005. Subducted carbonates, metasomatism of mantle wedges, and possible connections to diamond formation: An example from California. Am. Min. 90: 864-870. 
Dupuy, C., Dostal, J., Leblanc, M., 1981. Geochemistry of an ophiolitic complex from New-Caledonia. Contrib. Mineral. Petrol. 76: 77-83.

Edmond, J. M., Measures, C., McDuff, R. E., Chan, L. H., Collier, R., Grant, B., Gordon, L. I., Corliss, J. B., 1979. Ridge crest hydrothermal activity and the balances of the major and minor elements in the ocean - Galapagos data. E.P.S.L. 46: 1-18.

Evans, K. A., 2006. Redox decoupling and redox budgets: Conceptual tools for the study of earth systems. Geology 34: 489-492.

Fischer, T. P., Marty, B., 2005. Volatile abundances in the sub-arc mantle: insights from volcanic and hydrothermal gas discharges. J. Volc. Geotherm. Res. 140: 205-216.

Frost, B. R., Ballhaus, C., 1998. Comment on "Constraints on the origin of the oxidation state of mantle overlying subduction zones: An example from Simcoe, Washington, USA". Geochim. Cosmochim. Acta. 62: 329-331.

Frost, B. R., Beard, J. S., 2007. On silica activity and serpentinization. J. Pet. 48: 1351-1368.

Ghiorso, M. S., Hirschmann, M. M., Reiners, P. W., Kress, V. C., 2002. The pMELTS: A revision of MELTS for improved calculation of phase relations and major element partitioning related to partial melting of the mantle to 3 GPa. Geochem. Geophys. Geosys. 3.

Giggenbach, W. F., 1992. Magma degassing and mineral deposition in hydrothermal systems along convergent plate boundaries. Economic Geology 87: 1927-1944.

Gorman, P. J., Kerrick, D. M., Connolly, J. A. D., 2006. Modeling open system metamorphic decarbonation of subducting slabs. Geochem. Geophys. Geosys. 7. 
Gurenko, A. A., Schmincke, H. U., 2000. S concentrations and its speciation in Miocene basaltic magmas north and south of Gran Canaria (Canary Islands): Constraints from glass inclusions in olivine and clinopyroxene. Geochim. Cosmochim. Acta. 64: 2321-2337.

Hacker, B. R., Peacock, S. M., Abers, G. A., Holloway, S. D., 2003. Subduction factory - 2. Are intermediate-depth earthquakes in subducting slabs linked to metamorphic dehydration reactions? J. Geophys. Res: Solid Earth. 108.

Hattori, K. H., Guillot, S., 2007. Geochemical character of serpentinites associated with high- to ultrahigh-pressure metamorphic rocks in the Alps, Cuba, and the Himalayas: Recycling of elements in subduction zones. Geochem. Geophys. Geosys. 8.

Hay, W. W., Sloan, J. L., Wold, C. N., 1988. Mass age distribution and composition of sediments on the ocean-floor and the global rate of sediment subduction. J. Geophys. Res: Solid Earth. 93: 14933-14940.

Hayes, J. M., Waldbauer, J. R., 2006. The carbon cycle and associated redox processes through time. Phil. Trans. Roy. Soc. 361: 931-950.

Hermann, J., Spandler, C., Hack, A., Korsakov, A. V., 2006. Aqueous fluids and hydrous melts in high-pressure and ultra-high pressure rocks: Implications for element transfer in subduction zones. Lithos 92: 399-417.

Hilton, D. R., Fischer, T. P., Marty, B. (2002), Noble gases and volatile recycling at subduction zones, in Noble Gases in Geochemistry and Cosmochemistry, edited, pp. 319-370.

Hirschmann, M. M., 2009. Ironing out the oxidation of Earth's mantle. Science 325: $545-546$.

Hoffman, N. R. A., McKenzie, D. P., 1985. The destruction of geochemical heterogeneities by differential fluid motions during mantle convection. Geophys. Jour. Roy. Astr. Soc. 82: 163-206. 
Holland, H. D., 2002. Volcanic gases, black smokers, and the Great Oxidation Event. Geochim. Cosmochim. Acta. 66: 3811-3826.

Holser, W. T., Schidlowski, M., Mackenzie, F. T., Maynard, J. B. (1988), Biogeochemical cycles of carbon and sulphur, in Chemical cycles and the evolution of the Earth, edited by C. B. Gregor, R. M. Garrels, F. T. Mackenzie and J. B. Maynard, pp. 105-175, John Wiley and Sons, New York.

Honnorez, J., 2003. Hydrothermal alteration vs. ocean-floor metamorphism. A comparison between two case histories: the TAG hydrothermal mound (Mid-Atlantic Ridge) vs. DSDP/ODP Hole 504B (Equatorial East Pacific). Compt. Rend. Geosc. 335: 781-824.

Ito, E., Harris, D. M., Anderson, A. T., 1983. Alteration of oceanic-crust and geologic cycling of chlorine and water. Geochim. Cosmochim. Acta. 47: 1613-1624.

Jarrard, R. D., 2003. Subduction fluxes of water, carbon dioxide, chlorine, and potassium. Geochem. Geophys. Geosys. 4.

Johnson, H. P., Semyan, S. W., 1994. Age variation in the physical-properties of oceanic basalts - implications for crustal formation and evolution. J. Geophys. Res: Solid Earth. 99: 3123-3134.

Kelley, K. A., Cottrell, E., 2009. Water and the oxidation state of subduction zone magmas. Science 325: 605-607.

Kerrick, D. M., Caldeira, K., 1998. Metamorphic $\mathrm{CO}_{2}$ degassing from orogenic belts. Chem. Geol. 145: 213-232.

Kerrick, D. M., Connolly, J. A. D., 2001. Metamorphic devolatilisation of subducted marine sediments and teh transport of voatiles into the Earth's mantle. Nature 411: 293-296. 
Kessel, R., Schmidt, M. W., Ulmer, P., Pettke, T., 2005. Trace element signature of subduction-zone fluids, melts and supercritical liquids at 120-180 km depth. Nature 437: 724-727.

Kopf, A. J., 2002. Significance of mud volcanism. Rev. Geophys. 40. Article 1005.

Kopf, A. J., 2003. Global methane emission through mud volcanoes and its past and present impact on the Earth's climate. Int. Jour. Earth. Sci. 92: $806-816$.

Kump, L. R., Holland, H. D., 1992. Iron in precambrian rocks - implications for the global oxygen budget of the ancient Earth. Geochim. Cosmochim. Acta. 56: 3217-3223.

Kump, L. R., Kasting, J. F., Barley, M. E., 2001. Rise of atmospheric oxygen and the "upside-down" Archean mantle. Geochem. Geophys. Geosys. 2.

Lecuyer, C., Ricard, Y., 1999. Long-term fluxes and budget of ferric iron: implication for the redox states of the Earth's mantle and atmosphere. E.P.S.L. 165: 197-211.

Lee, C. T. A., Leeman, W. P., Canil, D., Li, Z. X. A., 2005. Similar V/Sc systematics in MORB and arc basalts: Implications for the oxygen fugacities of their mantle source regions. J. Pet. 46: 2313-2336.

Li, Z. X. A., Lee, C. T. A., 2004. The constancy of upper mantle fO(2) through time inferred from V/Sc ratios in basalts. E.P.S.L. 228: 483-493.

Marchesi, C., Garrido, C. J., Godard, M., Belley, F., Ferre, E., 2009. Migration and accumulation of ultra-depleted subduction-related melts in the Massif du Sud ophiolite (New Caledonia). Chem. Geol. 266: 180-195.

Marty, B., Jambon, A., Sano, Y., 1989. Helium-Isotopes and $\mathrm{CO}_{2}$ in Volcanic Gases of Japan. Chem. Geol. 76: 25-40. 
Marty, B., Tolstikhin, I. N., 1998. $\mathrm{CO}_{2}$ fluxes from mid-ocean ridges, arcs and plumes. Chem. Geol. 145: 233-248.

McDonough, W. F., Sun, S. S., 1995. The composition of the Earth. Chem. Geol. 120: 223-253.

McInnes, B. I. A., Gregoire, M., Binns, R. A., Herzig, P. M., Hannington, M. D., 2001. Hydrous metasomatism of oceanic sub-arc mantle, Lihir, Papua New Guinea: petrology and geochemistry of fluid-metasomatised mantle wedge xenoliths. E.P.S.L. 188: 169-183.

Mevel, C., 2003. Serpentinization of abyssal peridotites at mid-ocean ridges. Compt. Rend. Geosc. 335: 825-852.

Milkov, A. V., Claypool, G. E., Lee, Y. J., Xu, W. Y., Dickens, G. R., Borowski, W. S., 2003. In situ methane concentrations, at Hydrate Ridge, offshore Oregon: New constraints on the global gas hydrate inventory from an active margin. Geology 31: 833-836.

Milkov, A. V., Sassen, R., Apanasovich, T. V., Dadashev, F. G., 2003. Global gas flux from mud volcanoes: A significant source of fossil methane in the atmosphere and the ocean. Geophys. Res. Lett. 30.

Morner, N. A., Etiope, G., 2002. Carbon degassing from the lithosphere. Glob. Plan. Chan. 33: 185-203.

Mottl, M. J., Wheat, C. G., Fryer, P., Gharib, J., Martin, J. B., 2004. Chemistry of springs across the Mariana forearc shows progressive devolatilization of the subducting plate. Geochim. Cosmochim. Acta. 68: 4915-4933.

Mungall, J. E., 2002. Roasting the mantle: Slab melting and the genesis of major Au and Au-rich Cu deposits. Geology 30: 915-918.

Newton, R. C., Manning, C. E., 2005. Solubility of anhydrite, $\mathrm{CaSO}_{4}$, in $\mathrm{NaCl}-\mathrm{H}_{2} \mathrm{O}$ solutions at high pressures and temperatures: Applications to fluid-rock interaction. J. Pet. 46: 701-716. 
Parkinson, I. J., Arculus, R. J., 1999. The redox state of subduction zones: insights from arc-peridotites. Chem. Geol. 160: 409-423.

Paul, H. J., Gillis, K. M., Coggon, R. M., Teagle, D. A. H., 2006. ODP Site 1224: A missing link in the investigation of seafloor weathering. Geochem. Geophys. Geosys. 7.

Paulick, H., Bach, W., Godard, M., De Hoog, J. C. M., Suhr, G., Harvey, J., 2006. Geochemistry of abyssal peridotites (Mid-Atlantic Ridge, 15 degrees $20^{\prime}$ N, ODP Leg 209): Implications for fluid/rock interaction in slow spreading environments. Chem. Geol. 234: 179-210.

Peacock, S. M., 1990. Fluid processes in subduction zones. Science 248: 329337.

Petsch, S. T., Berner, R. A., 1998. Coupling the geochemical cycles of C, P, Fe, and S: The effect on atmospheric O-2 and the isotopic records of carbon and sulfur. Am. J. Sci. 298: 246-262.

Plank, T., Langmuir, C. H., 1998. The chemical composition of subducting sediment and its consequences for the crust and mantle. Chem. Geol. 145: 325-394.

Prinzhofer, A., Nicolas, A., Cassard, D., Moutte, J., Leblanc, M., Paris, J. P., Rabinovitch, M., 1980. Structures in the New-Caledonia PeridotitesGabbros - Implications for Oceanic Mantle and Crust. Tectonophysics 69: 85-112.

Raiswell, R., Canfield, D. E., 1998. Sources of iron for pyrite formation in marine sediments. Am. J. Sci. 298: 219-245.

Ranero, C. R., Sallares, V., 2004. Geophysical evidence for hydration of the crust and mantle of the Nazca plate during bending at the north Chile trench. Geology 32: 549-552. 
Rea, D. K., Ruff, L. J., 1996. Composition and mass flux of sediment entering the world's subduction zones: implications for global sediment budgets, great earthqueakes, and volcanism. E.P.S.L. 140: 1-12.

Ronov, A. B., Yaroshevsky, A. A., 1976. A new model for the chemical structure of the Earth's crust. Geochem. Int. 13: 89-121.

Rupke, L. H., Morgan, J. P., Hort, M., Connolly, J. A. D., 2004. Serpentine and the subduction zone water cycle. E.P.S.L. 223: 17-34.

Russell, M. J., Hall, A. J., Boyce, A. J., Fallick, A. E., 2005. 100th anniversary special paper: On hydrothermal convection systems and the emergence of life. Economic Geology 100: 419-438.

Saal, A. E., Hauri, E. H., Langmuir, C. H., Perfit, M. R., 2002. Vapour undersaturation in primitive mid-ocean-ridge basalt and the volatile content of Earth's upper mantle. Nature 419: 451-455.

Salters, V. J. M., Stracke, A., 2004. Composition of the depleted mantle. Geochem. Geophys. Geosys. 5.

Sano, Y., Nishio, Y., Gamo, T., Jambon, A., Marty, B., 1998. Noble gas and carbon isotopes in Mariana Trough basalt glasses. App. Geochem. 13: 441-449.

Sano, Y., Williams, S. N., 1996. Fluxes of mantle and subducted carbon along convergent plate boundaries. Geophys. Res. Lett. 23: 2749-2752.

Schneider, M. E., Eggler, D. H., 1986. Fluids in equilibrium with peridotite minerals - implications for mantle metasomatism. Geochim. Cosmochim. Acta. 50: 711-724.

Shaw, A. M., Hilton, D. R., Fischer, T. P., Walker, J. A., Alvarado, G. E., 2003. Contrasting He-C relationships in Nicaragua and Costa Rica: insights into C cycling through subduction zones. E.P.S.L. 214: 499-513. 
Skelton, A., Whitmarsh, R., Arghe, F., Crill, P., Koyi, H., 2005. Constraining the rate and extent of mantle serpentinization from seismic and petrological data: implications for chemosyntesis and tectonic processes. Geofluids. 5: 153-164.

Skelton, A. D. L., Valley, J. W., 2000. The relative timing of serpentinisation and mantle exhumation at the ocean-continent transition, Iberia: constraints from oxygen isotopes. E.P.S.L. 178: 327-338.

Staudigel, H., Albarede, F., Blichert-Toft, J., Edmond, J., McDonough, B., Jacobsen, S. B., Keeling, R., Langmuir, C. H., Nielsen, R. L., Plank, T., Rudnick, R., Shaw, H. F., Shirey, S., Veizer, J., White, W., 1998. Geochemical Earth Reference Model (GERM): description of the initiative. Chem. Geol. 145: 153-159.

Staudigel, H., Hart, S. R., Schmincke, H. U., Smith, B. M., 1989. Cretaceous ocean crust at DSDP Site-417 and Site-418 - carbon uptake from weathering versus loss by magmatic outgassing. Geochim. Cosmochim. Acta. 53: 3091-3094.

Sun, W., Arculus, R. J., Kamenetsky, V. S., Binns, R. A., 2004. Release of gold-bearing fluids in convergent margin magmas prompted by magnetite crystallization. Nature 431: 975-979.

Svensen, H., Planke, S., Malthe-Sorenssen, A., Jamtveit, B., Myklebust, R., Eidem, T. R., Rey, S. S., 2004. Release of methane from a volcanic basin as a mechanism for initial Eocene global warming. Nature 429: 542-545.

Vils, F., Pelletier, L., Kalt, A., Muntener, O., Ludwig, T., 2008. The Lithium, Boron and Beryllium content of serpentinized peridotites from ODP Leg 209 (Sites 1272A and 1274A): Implications for lithium and boron budgets of oceanic lithosphere. Geochim. Cosmochim. Acta. 72: 5475-5504.

von Huene, R., Scholl, J. W., 1991. Observations at convergent margins concerning sediment subduction, subduction erosion and the growth of con- 
tinental crust. Rev. Geophys. 29: 279-316.

Wallace, P., Carmichael, I. S. E., 1992. Sulfur in basaltic magmas. Geochim. Cosmochim. Acta. 56: 1863-1874.

Wallace, P. J., 2005. Volatiles in subduction zone magmas: concentrations and fluxes based on melt inclusion and volcanic gas data. J. Volc. Geotherm. Res. 140: 217-240.

Wallman, K., 2001. Controls on the Cretaceous and Cenozoic evolution of seawater composition, atmospheric $\mathrm{CO}_{2}$ and climate. Geochim. Cosmochim. Acta. 65: 3005-3025.

Wood, B. J., Bryndzia, L. T., Johnson, K. E., 1990. Mantle oxidation-state and its relationship to tectonic environment and fluid speciation. Science 248: $337-345$.

Wood, B. J., Wade, J., Kilburn, M. R., 2008. Core formation and the oxidation state of the Earth: Additional constraints from Nb, V and Cr partitioning. Geochim. Cosmochim. Acta. 72: 1415-1426.

Wykes, J. L., Newton, R. C., Manning, C. E., 2008. Solubility of andradite, $\mathrm{Ca}_{3} \mathrm{Fe}_{2} \mathrm{Si}_{3} \mathrm{O}_{12}$, in a $10 \mathrm{~mol} \% \mathrm{NaCl}$ solution at 800 degrees $\mathrm{C}$ and 10 kbar: Implications for the metasomatic origin of grandite garnet in calc-silicate granulites. Am. Min. 93: 886-892.

Wysoczanski, R. J., Wright, I. C., Gamble, J. A., Hauri, E. H., Luhr, J. F., Eggins, S. M., Handler, M. R., 2006. Volatile contents of Kermadec ArcHavre Trough pillow glasses: Fingerprinting slab-derived aqueous fluids in the mantle sources of arc and back-arc lavas. J. Volc. Geotherm. Res. 152: $51-73$.

Yaxley, G. M., Brey, G. P., 2004. Phase relations of carbonate-bearing eclogite assemblages from 2.5 to 5.5 GPa: implications for petrogenesis of carbonatites. Contrib. Mineral. Petrol. 146: 606-619. 
Zhang, Z. M., Shen, K., Sun, W. D., Liu, Y. S., Liou, J. G., Shi, C., Wang, J. L., 2008. Fluids in deeply subducted continental crust: Petrology, mineral chemistry and fluid inclusion of UHP metamorphic veins from the Sulu orogen, eastern China. Geochim. Cosmochim. Acta. 72: 3200-3228.

Zhou, W. M., Van der Voo, R., Peacor, D. R., Wang, D. M., Zhang, Y. X., 2001. Low-temperature oxidation in MORB of titanomagnetite to titanomaghemite: A gradual process with implications for marine magnetic anomaly amplitudes. J. Geophys. Res: Solid Earth. 106: 6409-6421. 


\section{Figure Captions}

Figure 1. (a) conceptual model; (b) box model representation of conceptual model

Figure 2. Results of analysis of serpentinised mantle lithosphere from the MARK fracture zone and New Caledonia: (a) $\mathrm{MgO}$ vs. $\mathrm{Al}_{2} \mathrm{O}_{3}$; (b) $\mathrm{S}$ vs. loss on ignition; (c) $\mathrm{Fe}^{3+} / \mathrm{Fe}_{\text {tot }}$ vs. loss on ignition; (d) $\mathrm{C}$ vs. loss on ignition; (e) $R B_{\mathrm{M}}$ versus loss on ignition; (f) $R B_{\mathrm{C}}$ versus loss on ignition.

Figure 3. Graphical representation of element fluxes. $\Delta$ indicates the net addition of each element to the mantle. Units for all fluxes are $\mathrm{x} 10^{12}$ moles year ${ }^{-1}$.

Figure 4. Estimates of input and output subduction zone redox budgets for minimum and maximum crustal oxidation and minimum and maximum mantle oxidation

Figure 5. Comparison of net subduction zone input with MORB, plume and the sum of MORB, plume and arc outputs

Figure 6. Calculated relationship between mantle $\log f \mathrm{O}_{2}$ relative to QFM and $\mathrm{Fe}_{2} \mathrm{O}_{3}$ content at $1200^{\circ} \mathrm{C}$ and $1 \mathrm{GPa}$. Calculations were made using pMelts (Ghiorso et al. 2002). Line shows best fit to arbitary equation shown in equation 2.

Figure 7. Calculated evolution of mantle $\log f \mathrm{O}_{2}$ relative to QFM with time for different redox budget fluxes and mantle mixing scenarios: (a) redox budget added only to subduction zones; (b) redox budget added only to the upper mantle; (c) redox budget added to the whole mantle; (d) redox budget added to the whole mantle with a linear increase in mixing efficiency up to 1 Ga. 
1671 9. Tables 
ส্  녕 용

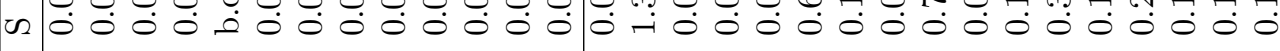
ט 음 -

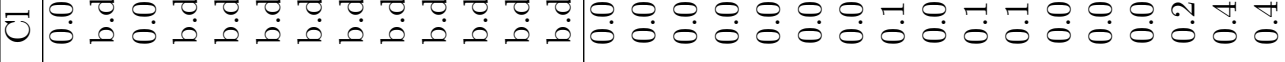

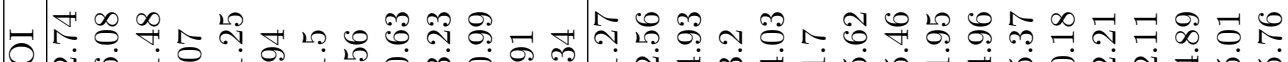

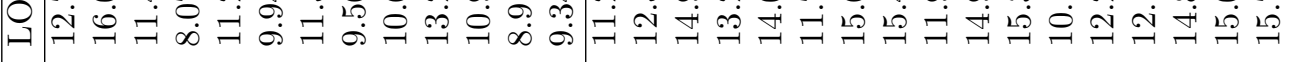

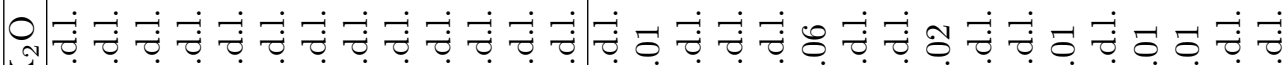

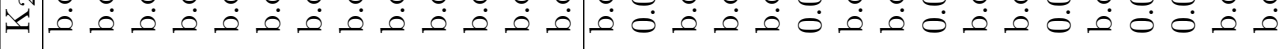

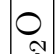

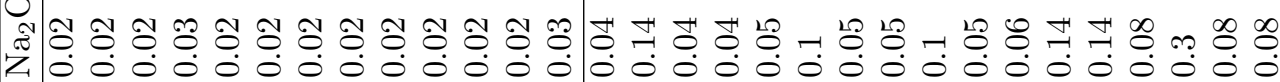

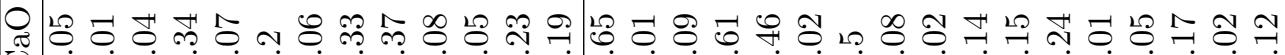

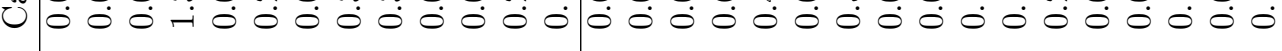

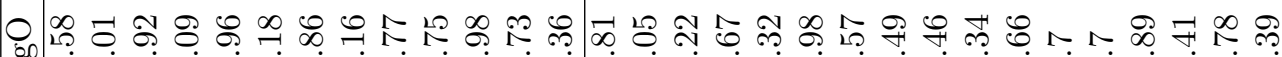

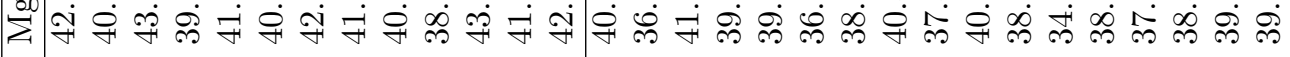
유 고

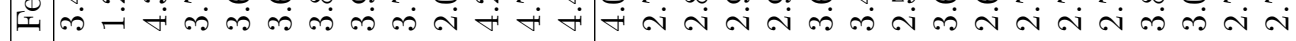

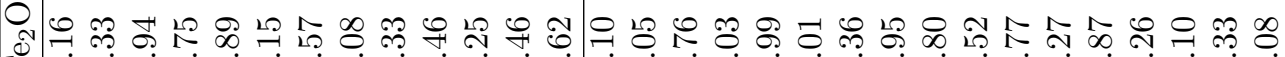
I I

蛋 ำ

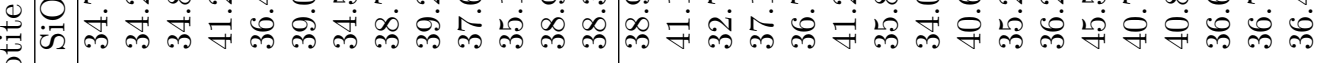

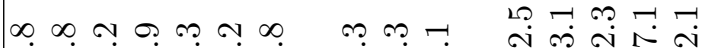
ล่ ลํำ

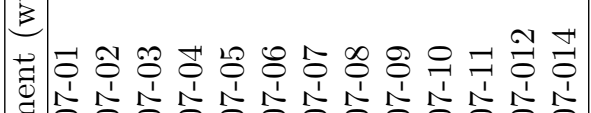

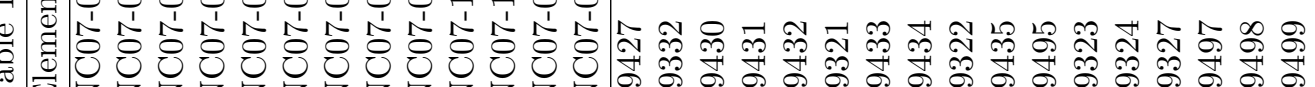

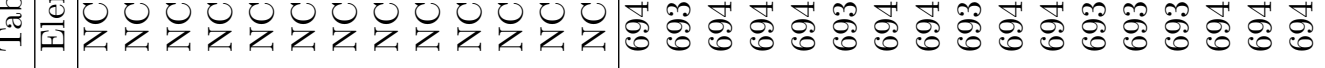


Table 2: Selected trace element contents in ppm b.d.l.: below detection limit

\begin{tabular}{|c|c|c|c|c|c|c|c|c|c|}
\hline & Co & $\mathrm{Cr}$ & $\mathrm{Cu}$ & $\mathrm{Ni}$ & V & $\mathrm{Zn}$ & $\mathrm{P}$ & Mn & $\mathrm{Ti}$ \\
\hline NC07-01 & 120 & 668 & 36 & 2540 & b.d.l. & 40 & 20 & 820 & b.d.l. \\
\hline NC07-02 & 114 & 1556 & 40 & 2383 & b.d.l. & 45 & 20 & 710 & b.d.l. \\
\hline NC07-03 & 122 & 1709 & 39 & 2626 & b.d.l. & 46 & 20 & 810 & b.d.l. \\
\hline NC07-04 & 110 & 1795 & 65 & 2091 & 36 & 51 & 20 & 930 & 100 \\
\hline NC07-05 & 119 & 2223 & 36 & 2444 & b.d.l. & 48 & 20 & 830 & b.d.l. \\
\hline NC07-06 & 115 & 2920 & 32 & 2190 & 22 & 50 & 20 & 920 & b.d.l. \\
\hline NC07-07 & 120 & 5809 & 30 & 2571 & b.d.l. & 54 & 20 & 820 & b.d.l. \\
\hline NC07-08 & 110 & 3513 & 35 & 2227 & b.d.l. & 46 & 20 & 830 & b.d.l. \\
\hline NC07-09 & 113 & 2324 & 46 & 2163 & 25 & 54 & 20 & 860 & b.d.l. \\
\hline NC07-10 & 112 & 2842 & 31 & 2215 & b.d.l. & 45 & 20 & 870 & b.d.l. \\
\hline NC07-11 & 122 & 1641 & 27 & 2671 & b.d.l. & 44 & 20 & 810 & b.d.l. \\
\hline NC07-012 & 129 & 3103 & 47 & 2335 & 23 & 58 & 20 & 950 & 100 \\
\hline NC07-014 & 135 & 1283 & 41 & 2370 & b.d.l. & 50 & 20 & 930 & b.d.l. \\
\hline 69319 & b.d.l. & 552 & 47 & 267 & 196 & 147 & 20 & 1700 & 3500 \\
\hline 69321 & 105 & 1954 & 52 & 2089 & 25 & 67 & 40 & 520 & 200 \\
\hline 69322 & b.d.l. & 2157 & 48 & 2152 & 24 & 46 & 20 & 880 & b.d.l. \\
\hline 69323 & b.d.l. & 1284 & 1009 & 1580 & 42 & 71 & 30 & 980 & 500 \\
\hline 69324 & 102 & 3662 & 91 & 2039 & 29 & 48 & 20 & 540 & b.d.l. \\
\hline 69325 & b.d.l. & b.d.l. & 56 & 70 & 169 & 82 & 40 & 840 & 3000 \\
\hline 69326 & b.d.l. & b.d.l. & 33 & 112 & 205 & 92 & 30 & 1540 & 2900 \\
\hline 69327 & 102 & 2120 & 88 & 2116 & 30 & 42 & 20 & 490 & b.d.l. \\
\hline 69328 & b.d.l. & b.d.l. & 41 & 113 & 190 & 83 & 20 & 1420 & 2700 \\
\hline 69329 & b.d.l. & b.d.l. & 41 & 96 & 176 & 59 & 60 & 1210 & 3300 \\
\hline 69331 & b.d.l. & b.d.l. & 37 & 92 & 194 & 59 & 100 & 1200 & 3600 \\
\hline 69332 & 111 & 1610 & 85 & 2114 & 22 & 44 & 20 & 510 & 100 \\
\hline 69427 & 125 & 1875 & 89 & 2247 & 23 & 59 & 20 & 840 & b.d.l. \\
\hline 69430 & 129 & 5806 & 99 & 2412 & 28 & 71 & 20 & 830 & b.d.l. \\
\hline 69431 & 122 & 2097 & 93 & 2224 & 32 & 59 & 20 & 840 & b.d.l. \\
\hline 69432 & 110 & 1759 & 76 & 2188 & 22 & 91 & 20 & 810 & b.d.l. \\
\hline 69433 & 111 & 1889 & 84 & 2112 & 27 & 73 & 20 & 770 & 200 \\
\hline 69434 & 118 & 1667 & 68 & 2311 & b.d.l. & 62 & 20 & 780 & b.d.l. \\
\hline 69435 & 117 & 1197 & 98 & 2321 & b.d.l. & 79 & 20 & 710 & 200 \\
\hline 69495 & 105 & 2148 & 66 & 2057 & 29 & 68 & 20 & 860 & 100 \\
\hline 69497 & 120 & 2586 & 70 & 2150 & 40 & 69 & 50 & 860 & 400 \\
\hline 69498 & 106 & 1737 & 82 & 2245 & b.d.l. & 58 & 20 & 720 & 200 \\
\hline 69499 & 101 & 1886 & 97 & 2147 & b.d.l. & 61 & 20 & 690 & 100 \\
\hline
\end{tabular}


Table 3: Summary of S content measurements in serpentinised peridotite

\begin{tabular}{|c|c|c|c|c|c|c|c|}
\hline Site & Source & $\mathrm{n}$ & $\mathrm{S}^{2-}$ & $\mathrm{S}^{-}$ & $\mathrm{S}^{2-}+\mathrm{S}^{-}$ & $\mathrm{S}^{6+}$ & $\mathrm{S}$ (total) \\
\hline MAR & Alt et al. (2007) & 36 & $0.04(5)$ & $0.05(14)$ & & $0.08(7)$ & \\
\hline $15^{\circ} 20^{\prime}$ & Vils et al. (2008) & 13 & & & & & $0.11(6)$ \\
\hline & Paulick et al. (2006) & 13 & & & & & $0.32(56)$ \\
\hline & This study & 18 & & & & & $0.26(34)$ \\
\hline $\begin{array}{l}\text { Izu-Bonin } \\
\text { Forearc }\end{array}$ & Alt and Shanks (2006) & 27 & & & $0.006(15)$ & $0.03(7)$ & \\
\hline $\begin{array}{l}\text { MAR } \\
\text { Kane Fracture } \\
\text { Zone }\end{array}$ & Alt and Shanks (2003) & 22 & & & $0.12(21)$ & $0.05(2)$ & \\
\hline $\begin{array}{l}\text { New } \\
\text { Caledonia }\end{array}$ & This Study & 13 & & & & & $\overline{0.01(1)}$ \\
\hline
\end{tabular}


Table 4: Estimates of compositions and uncertainties of input and output reservoirs for subduction zones

\begin{tabular}{lccccccc}
\hline wt\% element & $\mathrm{C}^{0}$ & $\mathrm{C}^{4+}$ & $\mathrm{Fe}^{2+}$ & $\mathrm{Fe}^{3+}$ & $\mathrm{S}^{2-}$ & $\mathrm{S}^{-}$ & $\mathrm{S}^{6+}$ \\
\hline Sediments & & & & & & & \\
$\sigma$ & 0.50 & 3.00 & 0.72 & 3.28 & n.a. & 1.15 & n.a. \\
& 0.25 & 1.40 & 0.06 & 0.26 & n.a. & 0.58 & n.a. \\
Altered Ocean Crust & n.a. & 0.21 & 4.90 & 1.40 & n.a. & 0.071 & 0.036 \\
$\sigma$ & n.a. & 0.04 & 0.59 & 0.62 & n.a. & 0.014 & 0.018 \\
& & & & & & & \\
Serpentinised Lithosphere & n.a. & 0.28 & 2.39 & 2.88 & 0.041 & 0.048 & 0.078 \\
$\sigma$ & n.a. & 0.28 & 0.40 & 0.40 & 0.055 & 0.140 & 0.073 \\
& & & & & & & \\
Arc Rocks & n.a. & 0.0007 & 4.62 & 3.09 & n.a. & 0.050 & n.a. \\
$\sigma$ & n.a. & 0.0003 & 1.39 & 1.39 & n.a. & 0.040 & n.a. \\
\hline n.a.: not applicable & & & & & & & \\
\hline
\end{tabular}




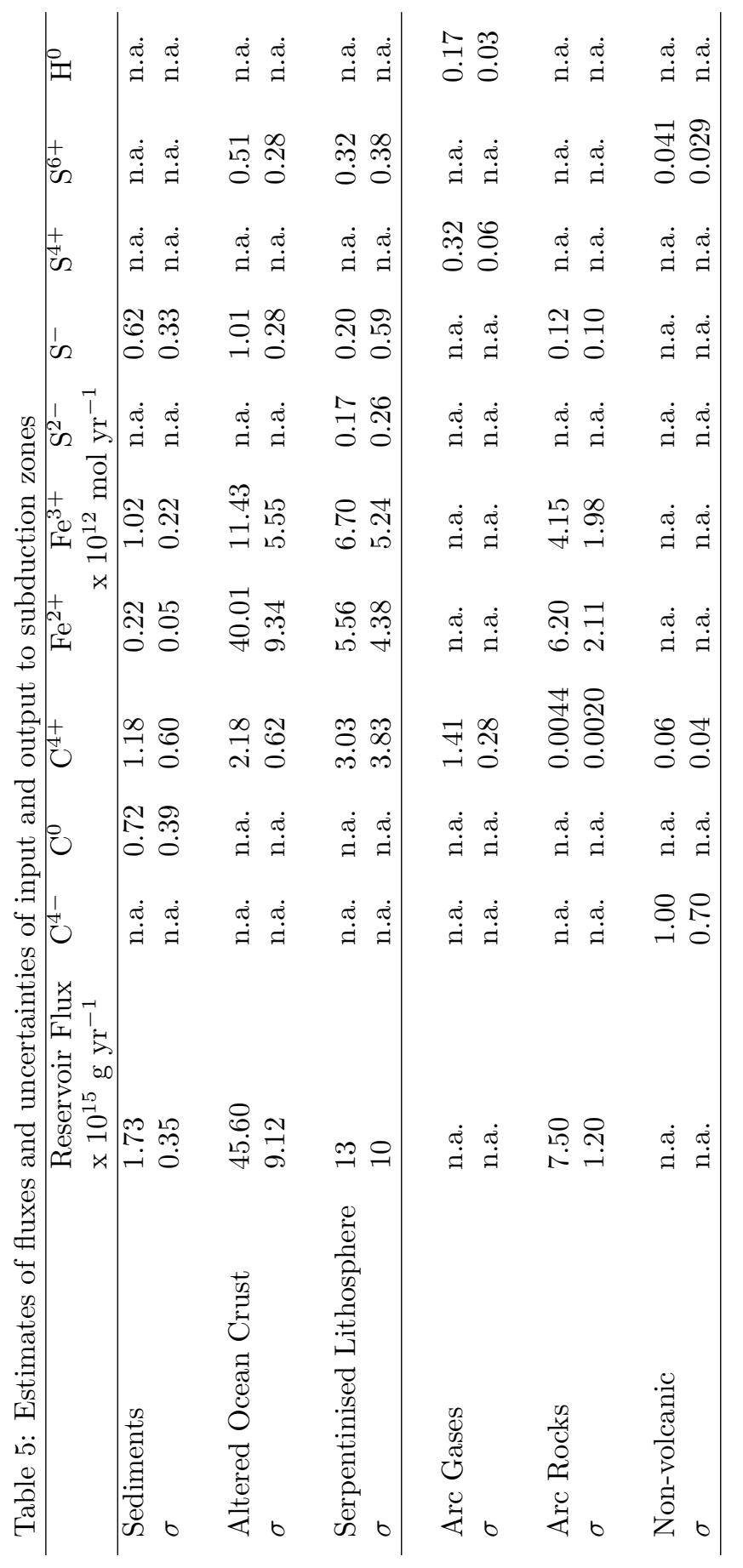


Table 6: Summary of element fluxes

\begin{tabular}{llll}
\hline & Fe & C & S \\
& \multicolumn{3}{c}{$\times 0^{12} \mathrm{~mol}^{-1}$} \\
\hline Sediments & 1.24 & 1.90 & 0.62 \\
$\sigma$ & 0.22 & 0.71 & 0.33 \\
Altered Ocean Crust & 51.44 & 2.18 & 1.52 \\
$\sigma$ & 10.87 & 0.62 & 0.40 \\
Serpentinised Lithosphere & 12.27 & 3.03 & 0.68 \\
\hline$\sigma$ & 6.83 & 3.83 & 0.75 \\
Arc Gases & 0.00 & 1.41 & 0.32 \\
$\sigma$ & 0.00 & 0.28 & 0.06 \\
Arc Rocks & 10.35 & 0.00 & 0.12 \\
$\sigma$ & 2.90 & 0.00 & 0.10 \\
Non-volcanic & 0.00 & 1.06 & 0.04 \\
$\sigma$ & 0.00 & 0.70 & 0.03 \\
\hline IN & 64.94 & 7.11 & 2.82 \\
$\sigma$ & 12.84 & 3.94 & 0.91 \\
OUT & 10.35 & 2.47 & 0.48 \\
$\sigma$ & 2.90 & 0.75 & 0.12 \\
\hline Net addition & 54.59 & 4.64 & 2.35 \\
$\sigma$ & 13.16 & 4.01 & 0.92 \\
$\%$ recycled & 15.94 & 34.74 & 16.93 \\
$\sigma$ & 5.46 & 21.99 & 6.88 \\
\hline
\end{tabular}




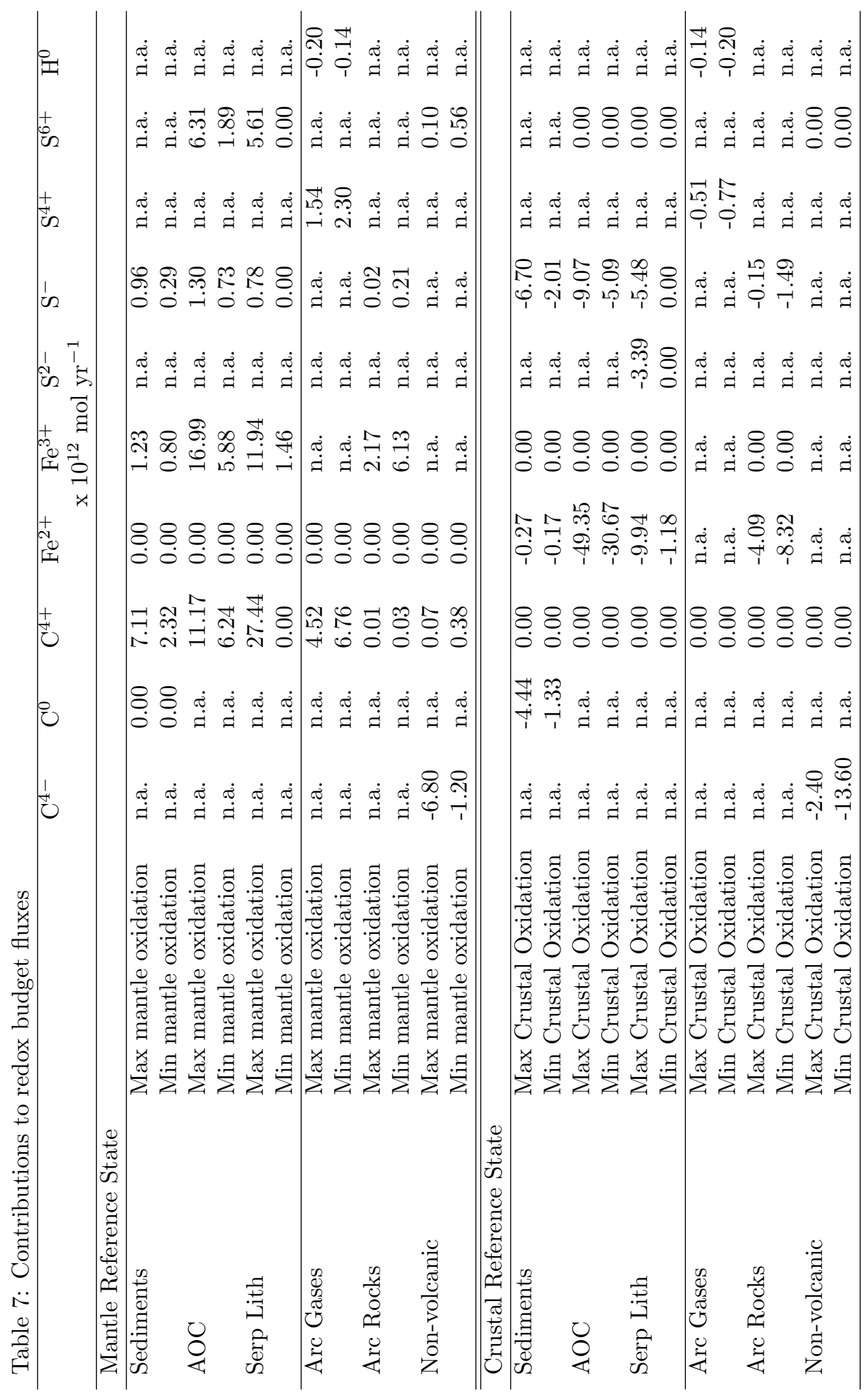




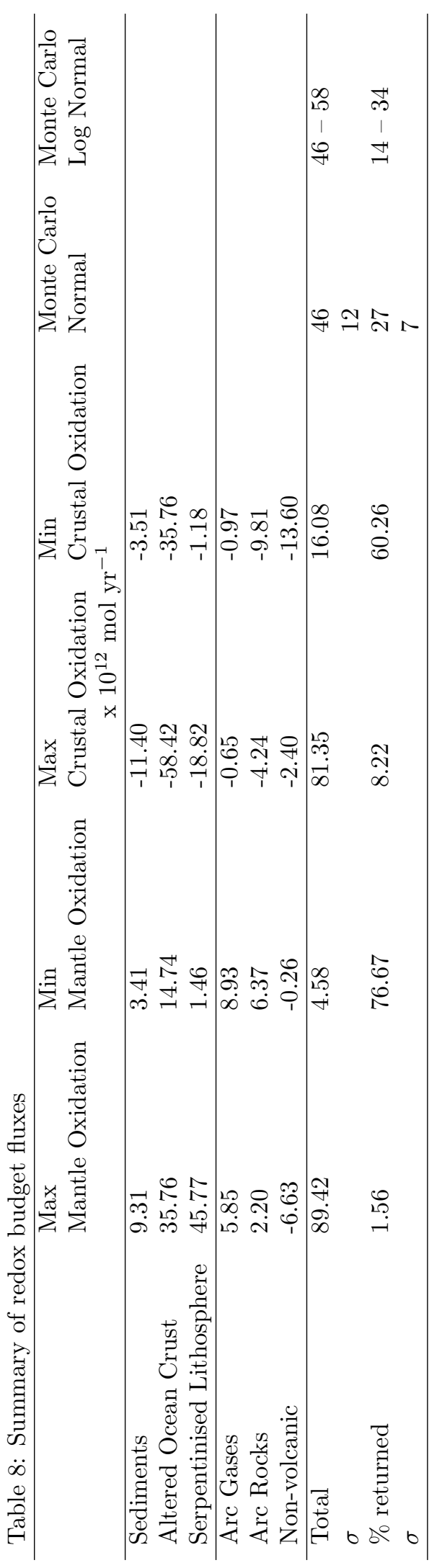


Table 9: Summary of other mantle fluxes

\begin{tabular}{|c|c|c|c|c|c|c|}
\hline & $\mathrm{C}^{4+}$ & $\mathrm{Fe}^{2+}$ & $\begin{array}{l}\mathrm{Fe}^{3+} \\
\mathrm{wt} \%\end{array}$ & $\mathrm{~S}^{2-}$ & $\mathrm{S}^{6+}$ & $\begin{array}{l}\text { Reservoir Flux } \\
\mathrm{x} 10^{-15} \text { g year }^{-1}\end{array}$ \\
\hline MORB & 0.08 & 5.86 & 0.44 & 0.09 & 0.00 & 45.60 \\
\hline$\sigma$ & 0.02 & 2.29 & 0.26 & 0.01 & 0.00 & 9.12 \\
\hline OIB & 2.30 & 4.90 & 2.00 & 0.33 & 0.06 & 4.56 \\
\hline$\sigma$ & 1.15 & 1.02 & 0.92 & 0.10 & 0.02 & 0.91 \\
\hline Flux $\times 10^{-12}$ moles year $^{-1}$ & $\mathrm{C}^{4+}$ & $\mathrm{Fe}^{2+}$ & $\mathrm{Fe}^{3+}$ & $\mathrm{S}^{2-}$ & $\mathrm{S}^{6+}$ & \\
\hline \multicolumn{7}{|c|}{$\mathrm{x} 10^{-12}$ moles year $^{-1}$} \\
\hline MORB & 0.86 & 47.85 & 3.59 & 1.22 & 0.06 & \\
\hline$\sigma$ & 0.24 & 20.97 & 2.24 & 0.28 & 0.07 & \\
\hline OIB & 2.38 & 4.00 & 1.63 & 0.47 & 0.09 & \\
\hline$\sigma$ & 1.28 & 1.15 & 0.82 & 0.17 & 0.04 & \\
\hline \multicolumn{7}{|c|}{ Element Fluxes x $10^{-12}$ moles year $^{-1}$} \\
\hline & $\mathrm{Fe}$ & $\mathrm{C}$ & $\mathrm{S}$ & & & \\
\hline MORB & 51.44 & 0.86 & 1.28 & & & \\
\hline$\sigma$ & 21.09 & 0.24 & 0.29 & & & \\
\hline OIB & 5.63 & 2.38 & 0.56 & & & \\
\hline$\sigma$ & 1.42 & 1.28 & 0.18 & & & \\
\hline Total & 57.07 & 3.24 & 1.84 & & & \\
\hline$\sigma$ & 21.14 & 1.31 & 0.34 & & & \\
\hline \multicolumn{7}{|c|}{$\mathrm{RB}_{M} \times 10^{-12}$ moles year ${ }^{-1}$} \\
\hline MORB & 7.53 & & & & & \\
\hline$\sigma$ & 2.49 & & & & & \\
\hline OIB & 11.88 & & & & & \\
\hline$\sigma$ & 5.21 & & & & & \\
\hline Total & 19.40 & & & & & \\
\hline$\sigma$ & 5.77 & & & & & \\
\hline
\end{tabular}


1677 10. Figures 


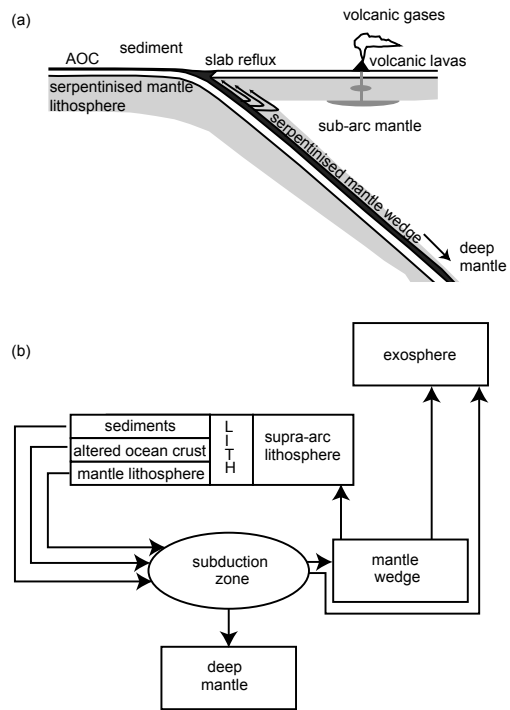

Figure 1: 

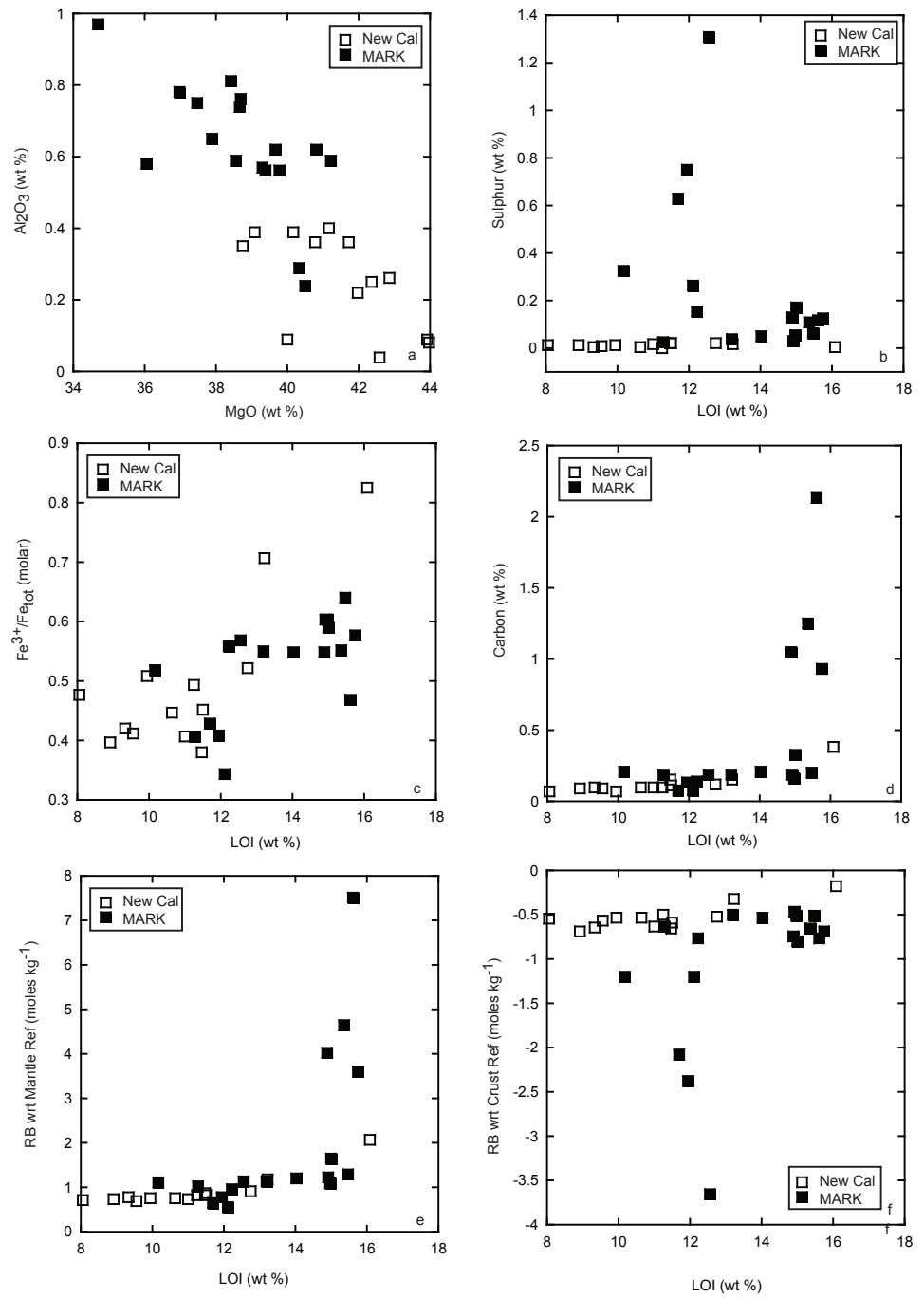

Figure 2: 


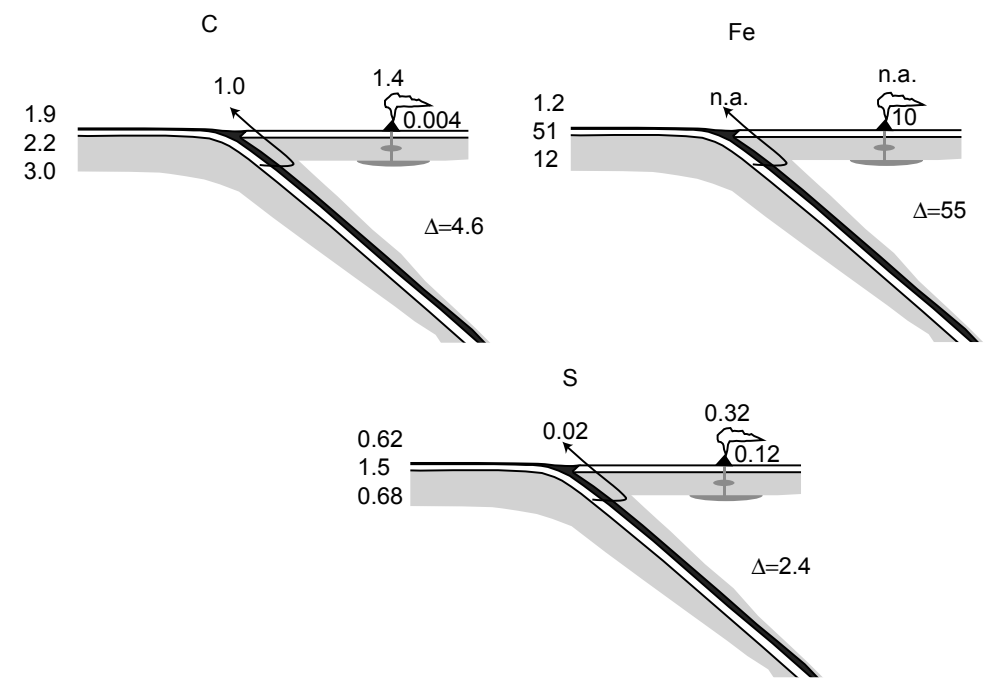

Figure 3: 

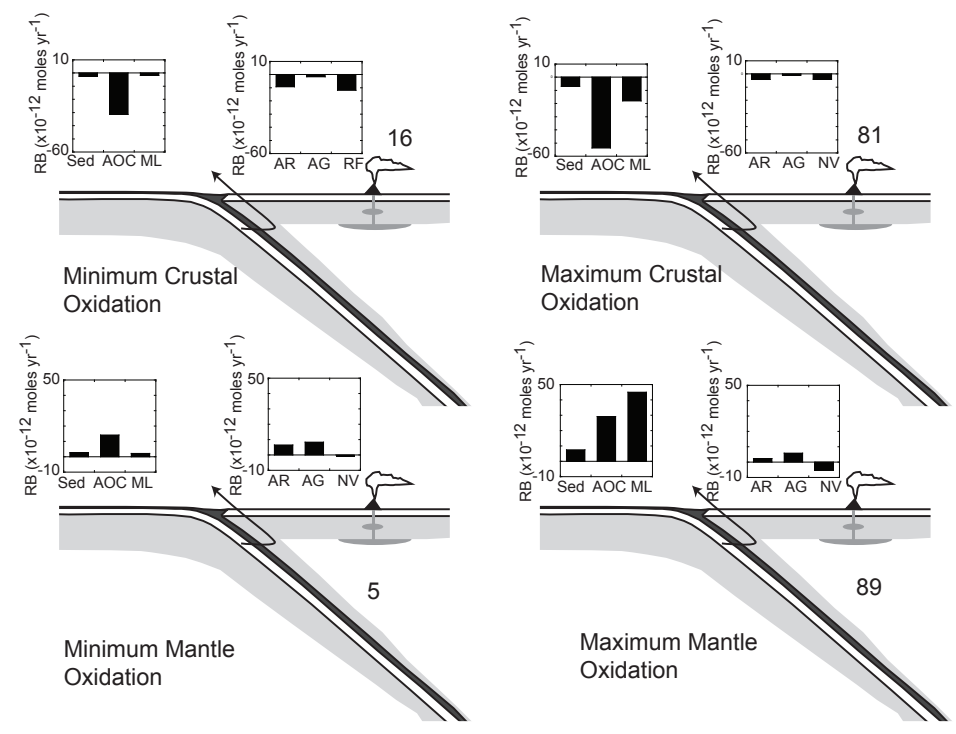

Figure 4: 


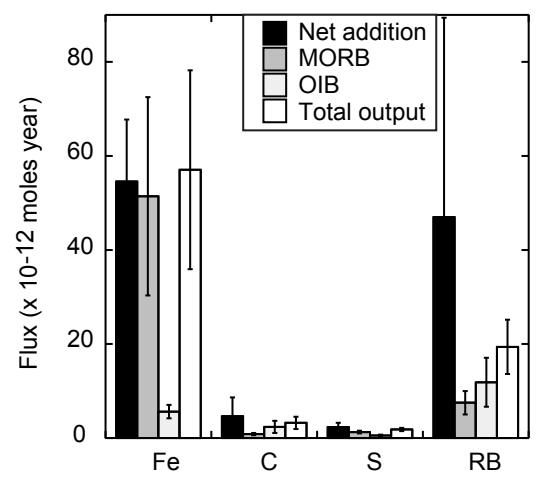

Figure 5: 


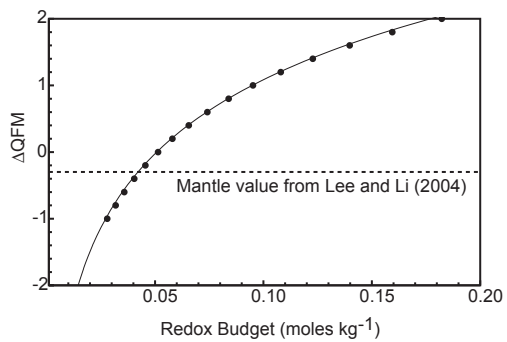

Figure 6: 

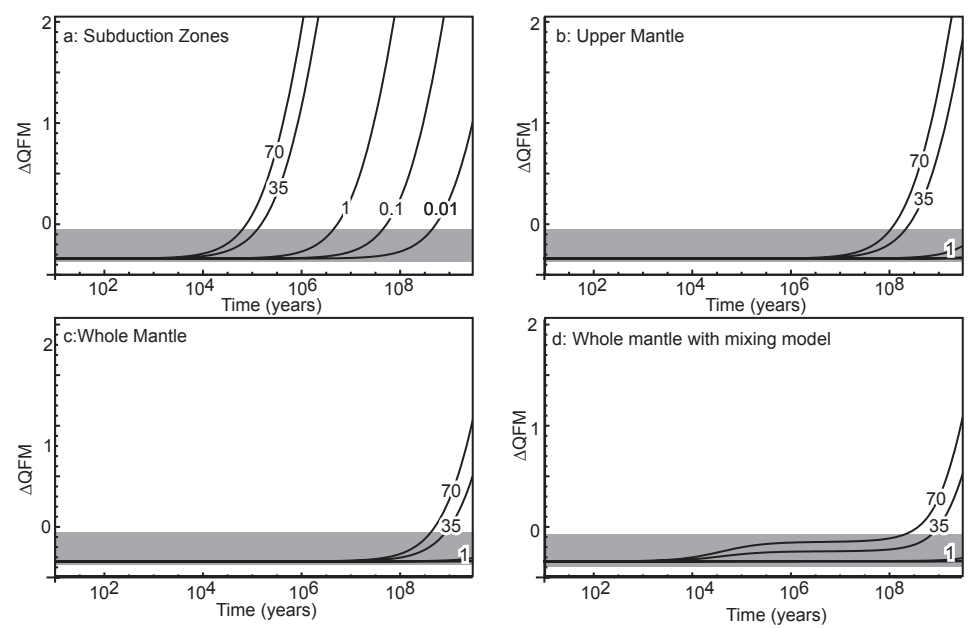

Figure 7: 